\title{
Digital Adoption, Automation, and Labor Markets in Developing and Emerging Economies
}

\author{
Alan Finkelstein Shapiro and Federico S. Mandelman
}

\section{Working Paper 2019-22}

December 2019

\begin{abstract}
We document a strong negative link between self-employment and the rate of digital adoption by firms in developing and emerging economies. No link between digital adoption and the unemployment rate is found, however. To explain this evidence, we build a general equilibrium search-and-matching model with endogenous labor force participation, self-employment, endogenous firm entry, and information-and-communications technology adoption. The main finding is that changes in the cost of technology adoption per se cannot rationalize the evidence. Instead, changes in firms' barriers to entry directly linked to the cost of technology adoption are key to explain the data.
\end{abstract}

JEL classification: E24, J23, J24, J64, 014

Key words: Information-and-telecommunications-technology capital (ICT), digital adoption, automation, labor search frictions, unemployment, self-employment, endogenous firm entry, developing and emerging economies

https://doi.org/10.29338/wp2019-22

The authors thank Mitali Das and Benjamin Hilgenstock for very generously sharing their dataset on routine task intensity measures for developing and emerging economies. The views expressed here are those of the authors and not necessarily those of the Federal Reserve Bank of Atlanta or the Federal Reserve System. Any remaining errors are the authors' responsibility.

Please address questions regarding content to Alan Finkelstein Shapiro, Department of Economics, Tufts University, Braker Hall, 8 Upper Campus Road, Medford, MA 02155, Alan.Finkelstein_Shapiro@tufts.edu, or Federico S. Mandelman, Research Department, Federal Reserve Bank of Atlanta, 1000 Peachtree Street, NE, Atlanta, GA, 30309, federico.mandelman@atl.frb.org

Federal Reserve Bank of Atlanta working papers, including revised versions, are available on the Atlanta Fed's website at www.frbatlanta.org. Click "Publications" and then "Working Papers." To receive e-mail notifications about new papers, use frbatlanta.org/forms/subscribe. 


\section{Introduction}

In recent years, the consequences of digital adoption and automation technologies for labor market outcomes have gained significant attention in the U.S. and other advanced economies (AEs) 1 1 A key concern is that greater digital adoption - a precursor to the adoption of automation technologies - may replace certain tasks, occupations, and jobs with capital, which may in turn contribute to labor market disruptions and greater unemployment. These concerns have extended to developing and emerging economies (DEMEs), where increasing rates of digital adoption raise the vulnerability of certain (routine/low-skilled) jobs to replacement via automation, and exposure to routinization appears to be converging to AE levels (Das and Hilgenstock, 2018). Recent studies suggest that more than 60 percent of jobs in DEMEs are likely to be susceptible to automation (World Bank, 2016; Schlogl and Sumner, 2018). However, very little is known about the connection between digital adoption, automation, and labor market outcomes in DEMEs. Furthermore, the fact that AEs and DEMEs differ non-trivially in their employment structure suggests that a framework tailored to DEMEs is needed.

Indeed, while salaried work is the prevalent source of employment in AEs, DEMEs exhibit high rates of self-employment. These rates hover around 45 percent of the labor force and can be as high as 80 percent in some DEMEs.2 Moreover, the majority of the self-employed are own-account workers who operate owner-only firms, as opposed to entrepreneurs who innovate. In fact, self-employment in DEMEs is often an important outside option to salaried employment amid limited salaried-firm creation and the absence of formal safety nets that provide support during unemployment spells. This issue is compounded by the fact that salaried-firm creation requires a set of basic conditions that are often inadequate in DEMEs: infrastructure (institutional and physical), access to credit, effective regulations, and low

\footnotetext{
${ }^{1}$ See, for example, OECD (2016a, 2016b, 2016c) and Jaimovich and Siu (2019). Digital adoption refers to the adoption of information and communication technologies (ICT), which can take several different forms, including the introduction of specific electronic devices (computers, smartphones, etc.) into the workplace, as well as software and other hardware that facilitates and/or replaces certain tasks previously done manually. In this paper, we use the terms digital adoption and technology adoption interchangeably.

${ }^{2}$ In contrast, the average self-employment rate in AEs is 15 percent of the labor force. The stark differences in self-employment rates between AEs and DEMEs are virtually identical when self-employment is expressed as a share of total non-agricultural employment, confirming that the differences in self-employment rates between the two groups go beyond differences in agricultural employment.
} 
levels of red tape. Given these facts, it is not surprising that in DEMEs salaried firm creation is negatively associated with self-employment rates.

However, recent advances in the adoption and use of information-and-communicationstechnology (ICT) capital by DEME firms and governments have shown promise in lowering the barriers to entry for new salaried firms compared to more standard approaches to deregulation. Concrete examples include the adoption of digital-payment and digital-formfiling systems by several DEME governments (which have lowered the costs of regulationcompliance and paperwork filings required to create salaried firms), the expansion of mobile banking (which has broken down the barriers to credit access and facilitated firm entry), digital platforms, e-commerce, and the expansion of e-governance programs (which reduce red tape). Given that digital and automation technologies are tightly linked, firms' digital adoption due to advances in ICT have lowered the cost of market access and also reduced the effective costs of adopting automation technologies. Taken these facts together, the goal of this paper is to explore how digital adoption and automation shape firm creation, the employment structure, and labor market outcomes in DEMEs.

Using a large sample of DEMEs, we first document that digital adoption by firms is strongly and negatively associated with the costs of salaried firm creation, and positively associated with new salaried firm creation. Second, we document a strong and significant negative relationship between digital adoption by firms and self-employment rates in a large sample of DEMEs (this link is absent in AEs). Critically, this relationship is not driven by differences in the level of economic development or other factors associated with selfemployment. Third, we document the absence of a significant link between digital adoption and unemployment rates in DEMEs.

To account for these facts, we build a general equilibrium search-and-matching model with endogenous labor force participation (LFP) and self-employment, ICT capital adoption, and endogenous salaried-firm entry where ICT-capital-adoption costs and salaried-firm entry costs are linked. Under a data-disciplined calibration, our framework quantitatively generates: (1) the strong negative correlation between firms' digital adoption and self-employment rates observed in DEMEs; and (2) the absence of a link between digital adoption and unemployment rates as suggested by the data. The central quantitative insight is that greater 
digital adoption is strongly associated with lower self-employment rates, with little impact on unemployment, only if greater digital adoption is also associated with lower barriers to salaried-firm creation. We find that this model result is corroborated by the data.

In our framework, a representative household spends resources to create salaried firms and makes labor force participation decisions over salaried employment and self-employment in frictional labor markets. A key element of our model is the inclusion of endogenous ICTcapital adoption by salaried firms.$^{3}$ In our model, salaried firms incur a sunk entry cost, which can serve as a proxy for barriers to market entry. Upon entry, they draw their productivity level from a common distribution, which in turn determines from where these firms source their inputs. If their productivity level is below an endogenously-determined threshold, firms use inputs produced with a "regular" (or traditional) technology that only requires salaried labor. If their productivity level is above the threshold, firms incur a fixed cost - the cost of technology adoption - and rely on inputs produced with an "ICT" technology that uses two types of salaried labor and ICT capital: the first labor input can be interpreted as being relatively more skilled and complementary to ICT capital, and the second labor input can be interpreted as being relatively unskilled and imperfectly substitutable with ICT capital (thus, the ICT technology can be seen as an automation technology under the presence of capitalskill complementarity). Given a set of sunk-entry and fixed ICT-adoption costs, salaried firms effectively sort themselves into one of two salaried categories that differ fundamentally in their production technologies. This setup delivers an endogenous number of regular and ICT-capital salaried firms and, importantly, an endogenous ICT-capital-adoption share that can be mapped into our empirical measure of digital adoption by firms.

Motivated by the negative link between digital adoption by firms and the costs of salariedfirm creation we document in the data, we link the fixed cost of ICT-capital adoption to salaried firms' sunk entry costs. Then, a reduction in the cost of adoption of the ICT-capital technology endogenously increases both the the share of firms that use the ICT-capital technology and the overall number of salaried firms. $4^{4}$

\footnotetext{
${ }^{3}$ As we explain in Section 3, we do so via a tractable adaptation of the Ghironi and Melitz (2005) framework.

${ }^{4}$ Of note, our main model findings do not hinge on having a causal link from barriers to ICT-capital technology adoption (and hence ICT-capital-adoption by firms) to barriers to salaried-firm entry: the only factor that matters is that the two costs are related to each other. This subtle but important point implies
} 
The model outcomes are intuitively plausible but also supported by the data. Critically, the creation of salaried firms that results from lower costs triggers greater ICT capital demand and a large reallocation of employment away from self-employment and into salaried employment, leaving unemployment virtually unchanged. Amid greater digital adoption, self-employment falls dramatically and unemployment remains for all intense and purposes unchanged, exactly as in the data. Breaking the link between firms' entry costs and technology-adoption costs fails to generate these patterns. The reason is simple: greater technology adoption alone is not powerful enough to generate a large-enough reallocation of employment away from self-employment and into salaried employment because the base that ultimately supports salaried employment in the economy - the number of salaried firms - remains largely unchanged absent changes to salaried firms' entry costs. Our findings therefore highlight the link between technology adoption and salaried-firm-entry barriers for a better understanding of the relationship between firms' digital adoption (and the susceptibility to automation) and labor market outcomes in DEMEs.

To the best of our knowledge, we are the first to explore the link between digital adoption (and, by implication, susceptibility to automation), the employment composition of labor markets, and unemployment in DEMEs. We are also the first to provide a theoretical framework that incorporates key features of DEME labor markets amid automation and digital adoption, which allows us to quantitatively assess the main factors behind the relationship between digital adoption and labor market outcomes in these economies, and to highlight the role that digital adoption may have in reducing firms' entry barriers and changing the employment composition in these economies.

The nascent empirical literature on digital adoption and routinization, automation, and labor markets has primarily centered on the U.S. and other AEs, with a focus on the skill distribution of employment and earnings and the labor share 5 Morin (2016), Cortes, Jaimovich, and Siu (2017), Eden and Gaggl (2018), Berg, Buffie, and Zanna (2018), Schlogl and Sumner

that our results remain valid regardless of whether greater a reduction in firm-entry costs lowers the costs of technology adoption or, conversely, technology adoption lowers firm-entry costs.

${ }^{5}$ Acemoglu and Restrepo (2018a) focus on industrial robot usage and labor markets; Eden and Gaggl (2018) study the evolution of ICT capital goods and the labor share; Fossen and Sorgner (2018) establish a link between digital adoption and employment and entrepreneurship in the U.S.; Jaimovich and Siu (2019) analyze the role of automation on polarization and jobless recoveries. 
(2018), Acemoglu and Restrepo (2018a,b), Guimaraes and Mazeda Gil (2019), and Leduc and Liu (2019) provide important theoretical underpinnings that complement the empirical literature for the U.S. and AEs 5 Importantly, existing work on DEMEs is considerably more limited, with virtually no existing theoretical work. Most prominently, World Bank (2016, 2019) present stylized facts on digital adoption across DEMEs, but abstract from labor market outcomes, while Das and Hilgenstock (2018) study the link between labor market polarization and exposure to routinization in a sample of 85 economies (which includes the largest sample of DEMEs among existing studies), and point to the increasing rate at which DEMEs are exposed to routinization.7 Similar to our work, the models in Acemoglu and Restrepo (2018a, 2018b), Guimaraes and Mazeda Gil (2019), and Leduc and Liu (2019) also allow for a choice over technology adoption. Our modeling approach differs from these papers by: (1) considering reductions in the cost of technology adoption as a factor that also lowers the cost of firm entry; and (2) incorporating endogenous labor force participation and self-employment amid equilibrium unemployment. These two features of prove crucial to rationalize our stylized facts quantitatively 8 More broadly, our model findings highlight the importance of barriers to firm entry, and not just technology adoption, for understanding the link between firms' digital adoption and labor market outcomes in DEMEs.

The rest of the paper is structured as follows. Section 2 presents a series of stylized facts on digital adoption, routine-task intensity (and hence susceptibility to automation) and labor markets with a focus on DEMEs. Section 3 outlines the model. Section 4 discusses the calibration of the model, presents our main model findings, and dissects the model mechanisms. Section 5 concludes.

\footnotetext{
${ }^{6}$ Other well-known papers on technology adoption unrelated to automation, and therefore less directly related to our work, include Comin and Hobijn (2004), who document patterns of technology adoption in AEs; and Comin and Hobijn (2010), Comin, Dmitriev, and Rossi-Hansberg (2013), and Comin and Mestieri (2018), who focus on technology diffusion across countries. Also, see Autor and Salomons (2018) and the references therein.

${ }^{7}$ Maloney and Molina (2016) also study the potential for polarization in DEMEs, with a focus on automation and outsourcing. Reijnders and de Vries (2018) highlight the role of technological change in the rise of non-routine jobs in a sample of 37 economies and Hardy et al. (2018) document an inverse U-shaped link between relative routine task intensity and the level development in a sample of 42 economies. These two studies include only a limited set of DEMEs.

${ }^{8}$ Theoretical work on DEME labor markets with an explicit focus on self-employment, but that abstracts from automation and technology adoption, includes Fiess et al. (2010), Finkelstein Shapiro (2014, 2018), Finkelstein Shapiro and Mandelman (2016), and Poschke (2019), among others.
} 


\section{Stylized Facts}

\subsection{Digital Adoption, Firm Creation Costs and Firm Creation, and Self-Employment in DEMEs}

The World Bank's Digital Adoption Index The World Bank provides an aggregate index of digital adoption that is readily comparable across 180 economies and available for years 2014 and 2016. The aggregate index is constructed by averaging three subindices, each of which covers a category for every economy: business, government, and individuals (see the World Development Report 2016 for more details). Given our objective, we focus exclusively on the Business Digital Adoption Index (BDAI), which is the subindex that focuses on digital adoption by firms. This particular subindex takes values on the 0-1 scale and is constructed based on four summary indicators for each economy: the number of secure servers, the speed at which files are downloaded, 3G coverage, and the share of firms with websites.

While this subindex is of course not comprehensive in terms of the types of technologies firms can adopt, and more detailed measures of technology adoption exist for advanced economies (AEs), a clear advantage of the BDAI is that it offers a reasonable, comparable proxy of digital adoption across countries that includes virtually all developing and emerging economies (DEMEs).9 Das and Hilgenstock (2018) are the first to construct a comparable and consistent measure of routine task intensity (RTI) - a proxy that provides information on exposure to routinization and therefore susceptibility to automation - that goes beyond AEs and covers a non-trivial number of DEMEs. While this RTI measure may be more precise in capturing susceptibility to automation, it only covers 57 DEMEs, whereas the BDAI covers 136 DEMEs. As such, we use the BDAI as a baseline to establish a more robust and general stylized fact. Having said that, Section 2.2 below shows that the RTI measure and the BDAI are strongly and positively related. Moreover, our main stylized facts remain unchanged if we use RTI as a measure of susceptibility to automation.

\footnotetext{
${ }^{9} \mathrm{~A}$ wider set of indicators within the World Bank's DAI include internet sales and purchases, cloud computing, and software to manage supply chains, among other relevant measures of digital adoption, but these additional indicators are available for AEs and not for DEMEs.
} 


\section{Digital Adoption, Firm Creation Costs and Firm Creation, and Labor Market}

Outcomes in DEMEs Given our focus on firms and labor market outcomes, Figure 1 uses data for 2016 (the latest year the BDAI is available) for a large sample of DEMEs and plots the BDAI against the following variables: (1) the cost of creating a business (as a share of income per capita) (upper left quadrant); (2) new firm density (a proxy for new salaried firm creation) (upper right quadrant); (3) the self-employment rate (lower left quadrant); and (4) the unemployment rate (lower right quadrant) (Appendix A.1.1 lists the DEMEs in the sample) 10

Figure 1 graphically summarizes the following stylized facts:

1. A strong negative and significant relationship between digital adoption by firms and the cost of creating firms

2. A strong positive and significant relationship between digital adoption by firms and new (salaried) firm density

3. A strong negative and significant relationship between digital adoption by firms and the self-employment rate

4. A mild positive but statistically-weak relationship between digital adoption by firms and the unemployment rate

\footnotetext{
${ }^{10}$ Not all DEMEs in our baseline sample have data on new firm density; hence the smaller number of observations in the upper right quadrant of Figure 1 relative to the other quadrants. All subfigures in Figure 1 are based on country samples after having purged outliers using standard techniques.
} 
Figure 1: Business Digital Adoption Index, Cost of Starting a Business, New Firm Density, and Labor Market Outcomes in DEMEs
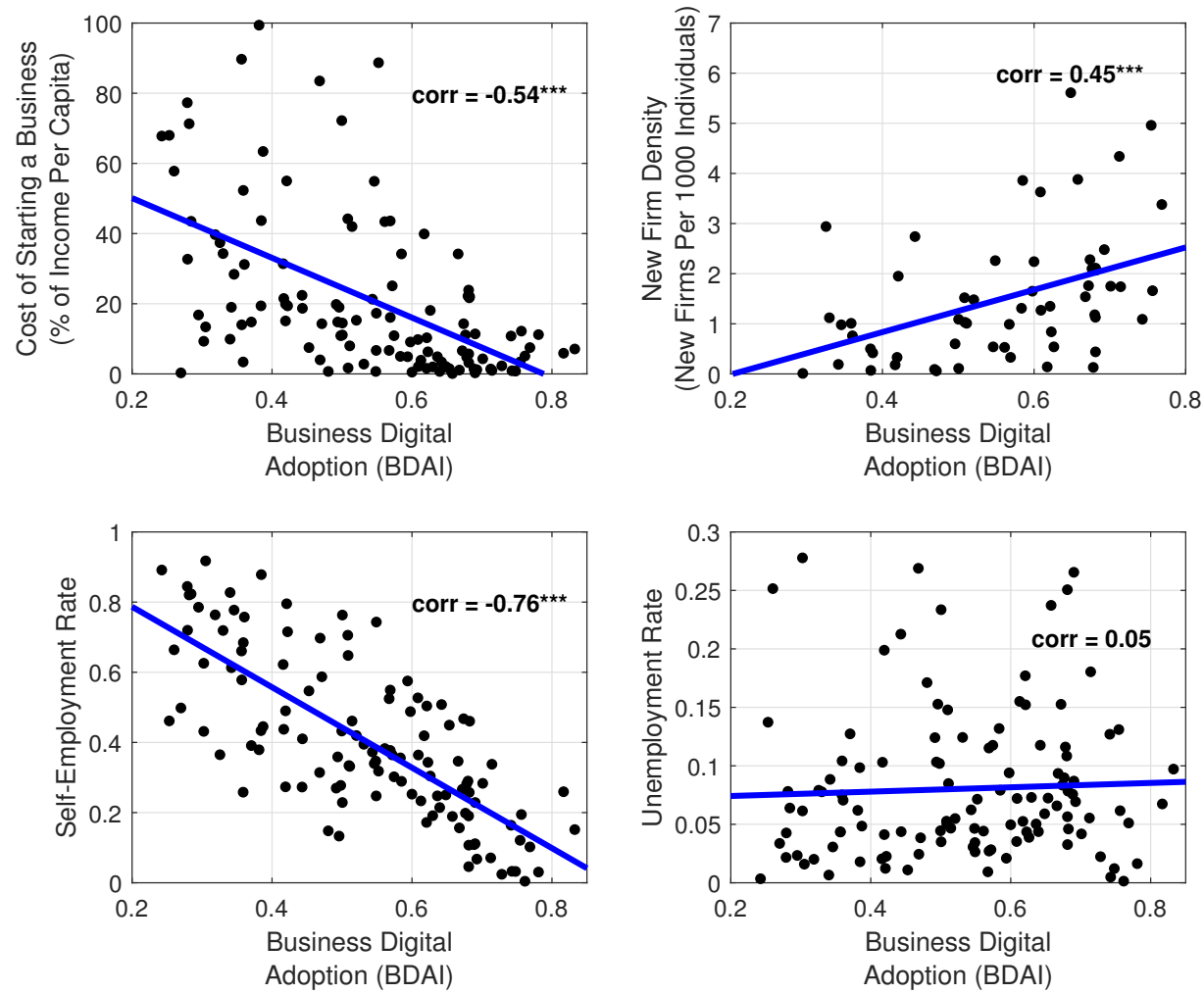

Sources: World Bank World Development Report 2016, World Bank Enterprise Surveys, World Bank Entrepreneurship Report, and World Bank World Development Indicators. Notes: New firm density is a proxy of new salaried firm creation that is comparable across economies and is defined as the number of new firm registrations per 1000 individuals. The self-employment rate is expressed as a share of the labor force. See Appendix A.1.1 for the list of economies used in this figure. ${ }^{* * *}$ and ${ }^{* *}$ denote significance at the 1 and 5 percent levels, respectively.

World Bank (2016) confirms that, across countries, digital adoption by firms is strongly and positively associated with the level of economic development (as proxied by real GDP per capita). Furthermore, it is well-known that the level of development is strongly and negatively associated with self-employment rates (and, incidentally, positively associated with salaried employment rates; see, for example, Poschke, 2016). Then, it is plausible that the link between digital adoption by firms and self-employment rates in Figure 1 may simply be driven by the level of development. Table 1 below presents a simple analysis of the link 
between digital adoption by firms and self-employment rates controlling for other factors that could be associated with cross-country differences in self-employment rates in DEMEs. In turn, Table 2 presents an analogous analysis that focuses on the link between digital adoption by firms and unemployment rates.

Table 1 shows that the strong and negative relationship between digital adoption by firms and self-employment rates remains strongly significant even after controlling for real GDP per capita, the industrial employment share in total employment, the services employment share in total employment, two measures of labor market regulations (the ratio of the minimum wage to value added per worker and and the number of weeks of severance payments), and the degree of government effectiveness (a measure of institutional quality). Similar results hold if we consider data on digital adoption for the other year available (2014) instead (see Table A1 in Appendix A.2), or if we control for the share of total employment in agriculture instead of the shares in industrial or services employment. In turn, Table 2 confirms the absence of a relationship between digital adoption by firms and unemployment rates that was graphically apparent in Figure 1 (Table A2 in Appendix A.2 shows similar results for 2014). In fact, factors that would plausibly be associated with cross-country differences in unemployment rates in DEMEs appear to be unimportant. 
Table 1: Self-Employment Rates and Business Digital Adoption Index (BDAI) (2016)

\begin{tabular}{lccccc}
\hline \hline Dep. Var.: Self-Empl. Rate & $(1)$ & $(2)$ & $(3)$ & $(4)$ & $(5)$ \\
\hline BDAI & $-1.170^{* * *}$ & $-0.495^{* * *}$ & $-0.353^{* * *}$ & $-0.337^{* * *}$ & $-0.393^{* * *}$ \\
& $(-12.92)$ & $(-3.87)$ & $(-3.17)$ & $(-2.93)$ & $(-3.16)$ \\
Log Real GDP PC & & $-0.129^{* * *}$ & $-0.0752^{* * *}$ & $-0.0641^{* * *}$ & $-0.0739^{* * *}$ \\
& & $(-7.47)$ & $(-3.26)$ & $(-2.76)$ & $(-3.20)$ \\
Industrial Empl. Share & & & $-0.608^{* * *}$ & $-0.691^{* * *}$ & $-0.668^{* * *}$ \\
& & & $(-3.70)$ & $(-4.22)$ & $(-4.07)$ \\
Services Empl. Share & & & $-0.327^{* * *}$ & $-0.368^{* * *}$ & $-0.365^{* * *}$ \\
& & & $(-2.70)$ & $(-3.10)$ & $(-3.05)$ \\
Min. Wage/VA per Worker & & & & 0.0355 & 0.0371 \\
& & & & $(0.98)$ & $(1.02)$ \\
Severance Payment & & & & $(1.47)$ & $(1.35)$ \\
& & & & & 0.0349 \\
Government Effectiveness & & & & $(1.21)$ \\
& & & & & \\
Constant & $1.036^{* * *}$ & $1.843^{* * *}$ & $1.567^{* * *}$ & $1.466^{* * *}$ & $1.588^{* * *}$ \\
& $(19.20)$ & $(16.47)$ & $(11.19)$ & $(10.73)$ & $(10.24)$ \\
\hline Adjusted $R^{2}$ & 0.584 & 0.697 & 0.745 & 0.763 & 0.764 \\
Observations & 118 & 117 & 117 & 114 & 114 \\
\hline \hline
\end{tabular}

Sources: World Bank World Development Indicators, Doing Business Report, and World Bank World Development Report 2016 (http://www.worldbank.org/en/publication/wdr2016/Digital-Adoption-Index). Notes: the self-employment rate is computed as the number of self-employed individuals divided by the labor force in 2016. BDAI corresponds to the Business Digital Adoption Index for 2016. Log Real GDP PC corresponds to the log of real GDP per capita in PPP terms in 2016. The severance payment represents pay for redundancy dismissal for a worker with 5 years of tenure (expressed in salary weeks). See Appendix A.1.1 for the list of countries used in this table. $t$ statistics in parentheses. Standard errors are heteroskedasticity-robust. $* * *$ and ${ }^{* *}$ denote significance at the 1 and 5 percent levels, respectively. 
Table 2: Unemployment Rates and Business Digital Adoption in DEMEs (2016)

\begin{tabular}{lccccc}
\hline \hline Dep. Var.: Unempl. Rate & $(1)$ & $(2)$ & $(3)$ & $(4)$ & $(5)$ \\
\hline BDAI & 0.0352 & 0.0282 & -0.0187 & -0.0368 & -0.0407 \\
& $(0.93)$ & $(0.48)$ & $(-0.29)$ & $(-0.56)$ & $(-0.56)$ \\
Log Real GDP PC & & 0.00187 & -0.0111 & -0.00755 & -0.00823 \\
& & $(0.22)$ & $(-0.97)$ & $(-0.61)$ & $(-0.61)$ \\
Industrial Empl. Share & & 0.0785 & 0.0884 & 0.0899 \\
& & & $(0.77)$ & $(0.83)$ & $(0.84)$ \\
Services Empl. Share & & $0.120^{* *}$ & $0.121^{* *}$ & $0.121^{* *}$ \\
& & & $(2.25)$ & $(2.15)$ & $(2.14)$ \\
Min. Wage/VA per Worker & & & 0.0149 & 0.0150 \\
& & & & $-0.000537^{*}$ & $-0.000541^{*}$ \\
Severance Payment & & & & $(-1.86)$ & $(-1.85)$ \\
& & & & 0.00242 \\
Government Effectiveness & & & & $0.18)$ \\
Constant & & & & & 0.0970 \\
& $0.0581^{* * *}$ & 0.0454 & 0.111 & 0.0886 & $(1.03)$ \\
\hline Adjusted $R^{2}$ & $(2.77)$ & $(0.78)$ & $(1.56)$ & $(1.15)$ & 0.029 \\
Observations & -0.000 & -0.007 & 0.029 & 0.037 & 114 \\
\hline \hline
\end{tabular}

Sources: World Bank World Development Indicators, Doing Business Report, and World Bank World Development Report 2016. Notes: the self-employment rate is computed as the number of self-employed individuals divided by the labor force in 2016. BDAI corresponds to the Business Digital Adoption Index for 2016. Log Real GDP PC corresponds to the log of real GDP per capita in PPP terms in 2016. The severance payment represents pay for redundancy dismissal for a worker with 5 years of tenure (expressed in salary weeks). See Appendix A.1.1 for the list of economies used in this table. Standard errors are heteroskedasticity-robust. ${ }^{* * *},{ }^{* *}$, and ${ }^{*}$ denote significance at the 1,5 , and 10 percent levels, respectively.

To stress the relevance of the strong relationship between self-employment rates and digital adoption by firms in DEMEs, and to further support the unique characteristics of DEMEs and our focus on these economies, we conduct a similar analysis to the one above only focusing in AEs. Table A3 in Appendix A.2 shows that, across AEs only, there is no significant link between the prevalence of self-employment and firms' digital adoption, or between unemployment rates and firms' digital adoption. 


\subsection{Digital Adoption and Routine Task Intensity: Evidence for Select DEMEs}

While digital adoption by firms does not by itself imply that some jobs, such as those focused on routine tasks or those that are relatively unskilled, would be automated, greater technology adoption, which includes digital technologies, can in fact make some types of jobs more vulnerable to automation.

Figure 2: Business Digital Adoption and Routine Task Intensity (RTI)
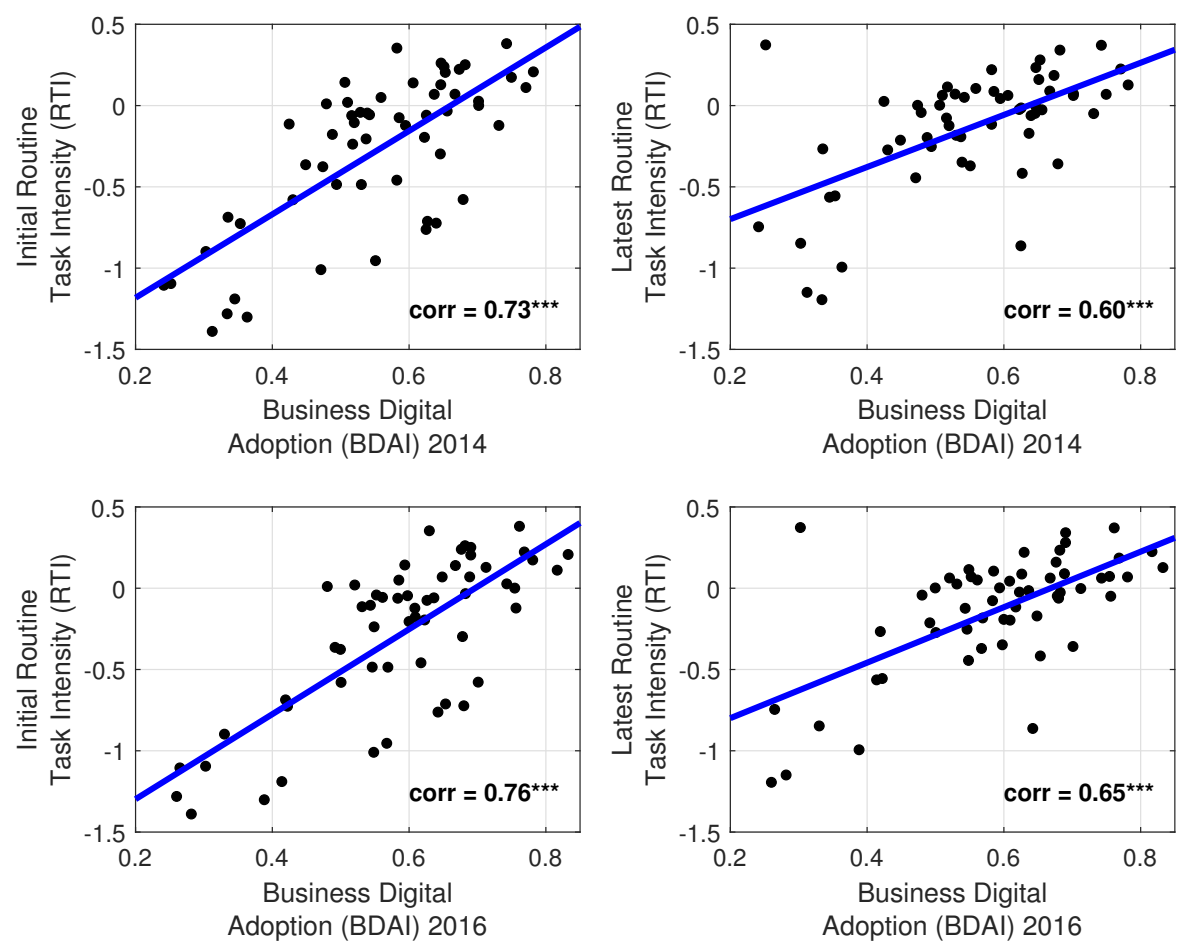

Sources: World Bank World Development Report 2016 and Das and Hilgenstock (2018). Notes: the Business Digital Adoption Index (DAI) corresponds to the index in 2014 in the upper two panels and 2016 in the lower two panels. The Initial and Latest Routine Task Intensity (RTI) measures are from Das and Hilgenstock (2018). *** denotes significance at the 1 percent level.

To establish a more explicit link between our measure of digital adoption by firms and the potential for automation, we consider the measure of routine task intensity (RTI) constructed by Das and Hilgenstock (2018). For completeness, we consider two measures of RTI used by Das and Hilgenstock: Initial RTI, which corresponds to the first observation of exposure 
to routinization available during the period 1990-1995 for a given economy, and Latest RTI, which corresponds to the last observation of exposure to routinization available during the period 2000-2015 (see Das and Hilgenstock, 2018, for more details) ${ }^{11}$ For both measures, a larger value of RTI implies greater exposure to routinization, implying that jobs may be more vulnerable to automation.

Figure 2 plots these two measures of RTI against our measure of digital adoption by firms for 2014 (upper two panels) and for 2016 (lower two panels) for completeness. The figure shows a strong positive and significant relationship between digital adoption by firms and routine task intensity in DEMEs, thereby confirming that greater digital adoption by firms is associated with greater exposure to routinization. To the extent that routinization increases the vulnerability of jobs to automation, greater digital adoption by firms is likely associated with greater exposure to labor-replacing technologies.

\section{The Model}

The economy has a representative household with a measure one of household members, and two broad firm categories - salaried firms and self-employed firms. We assume a closed economy to focus on labor markets (our findings remain unchanged if we assume a small open economy). The population has a unit mass, but labor force participation is endogenous. A choice over labor force participation allows households to optimally allocate its members across employment categories.

Salaried firms are comprised of monopolistically-competitive wholesale firms whose entry is endogenous. These firms source their inputs from perfectly-competitive intermediate-goods salaried firms who produce two different categories of intermediate goods for their salaried wholesale counterparts. The first category of intermediate goods is produced using a regular (or traditional) production technology with salaried labor as its only input-henceforth referred to as regular or $r$ intermediate goods. The second category of intermediate goods is produced using a production technology with information-and-communication-technology (ICT) capital and two types of salaried labor-henceforth referred to as ICT-capital or $i$

\footnotetext{
${ }^{11}$ We thank the authors for very generously sharing their dataset on RTI for DEMEs.
} 
intermediate goods. The first labor type is a complement to ICT capital (this can be interpreted as high-skilled or non-routine labor) and generates an ICT-capital-labor composite, and the second labor type is imperfectly substitutable with this composite (this second type of labor can be interpreted as low-skilled or routine labor). Intermediate-goods firms post vacancies to attract salaried workers for the production of $r$ and $i$ intermediate goods.

Once a given wholesale firm pays a sunk cost to enter the market, it draws its idiosyncratic productivity level (this productivity remains unchanged until the firm exits the market). A threshold productivity level determines whether the firm sources $r$ intermediate goods, which makes this wholesale firm an $r$ wholesale firm, or $i$ intermediate goods, which makes this wholesale firm an $i$ wholesale firm. Importantly, using $i$ intermediate goods entails paying an additional fixed cost, but results in greater productivity. The idiosyncratic productivity level above which wholesale firms use $i$ intermediate goods is endogenous. As such, wholesale firms effectively face a technology-adoption decision, and both the number of $i$ wholesale firms and the total number of wholesale firms in the economy are endogenous. Thus, the structure of salaried wholesale firms is a closed-economy adaptation of the well-known Ghironi and Melitz (henceforth GM) (2005) framework, where instead of having an endogenous number of non-exporters and exporters, we effectively have an endogenous number of firms who are nonICT-capital technology adopters and an endogenous number of firms who are ICT-capital technology adopters.

Households spend resources to create salaried wholesale firms, choose the measure of household members who search for salaried employment in intermediate-goods firms and the measure of household members who become self-employed (subject to a labor-forceparticipation cost), and consume final goods. By choosing the share of household members who become self-employed, households effectively create self-employed firms whose only input is self-employed labor. Final goods are obtained by combining salaried firms' and selfemployed firms' total output using a CES aggregator. Of note, even if the self-employed do not face search frictions, the presence of such frictions in salaried employment generates equilibrium unemployment. Finally, we assume that only salaried firms face technology (ICTcapital) adoption decisions. This is plausible and intuitive: if capital replaced self-employed labor, there would be no self-employment. More broadly, this assumption is consistent with 
the greater labor intensity of self-employed firms relative to salaried firms.

\subsection{Final Goods}

A perfectly-competitive final goods aggregator chooses aggregate salaried-wholesale-firm output $Y_{s, t}$ and total self-employment output $Y_{e, t}$ to maximize $\Pi_{y, t}=\left[Y_{t}-p_{s, t} Y_{s, t}-p_{e, t} Y_{e, t}\right]$ subject to $Y_{t}=\left[Y_{s, t}^{\frac{\phi_{y}-1}{\phi_{y}}}+Y_{e, t}^{\frac{\phi_{y}-1}{\phi_{y}}}\right]^{\frac{\phi_{y}}{\phi_{y}-1}}$, where $p_{s, t}$ is the relative price of aggregate salaried output, $p_{e, t}$ is the relative price of total self-employment output, $\phi_{y}>1$, and the (normalized) aggregate price index is given by $1=\left[p_{s, t}^{1-\phi_{y}}+p_{e, t}^{1-\phi_{y}}\right]^{\frac{1}{1-\phi_{y}}}$.

The first-order conditions yield standard demand conditions for each output category, $Y_{s, t}=\left(p_{s, t}\right)^{-\phi_{y}} Y_{t}$ and $Y_{e, t}=\left(p_{e, t}\right)^{-\phi_{y}} Y_{t}$

\subsection{Salaried Firms and Production}

Basic Setup In the spirit of the endogenous-firm-entry environment in GM (2005), there is a continuum of monopolistically-competitive salaried wholesale firms. Each wholesale firm produces a single differentiated output variety $\zeta$ and faces a sunk cost $f_{e}$ to enter the market (expressed in units of final goods). After wholesale firms enter, they draw their idiosyncratic productivity level $a$ from a common distribution $G(a)$ with support $\left[a_{\min }, \infty\right)$. Once drawn, a given wholesale firm's idiosyncratic productivity level remains unchanged until exit occurs with exogenous probability $0<\delta<1$. Since each wholesale firm produces a single variety $\zeta$ with idiosyncratic productivity $a$, in what follows we refer to wholesale firm $\zeta$ with idiosyncratic productivity level $a$ as wholesale firm $a$ for short.

Wholesale firms use inputs produced by salaried intermediate-goods firms, who produce two different types of intermediate goods. Depending on their level of idiosyncratic productivity, wholesale firms use $r$ intermediate-goods - intermediate goods produced with a regular technology that only uses salaried labor-or $i$ intermediate goods - intermediate goods produced with a technology that uses ICT capital and two types of salaried labor: the first labor type is a complement to ICT capital (this can be interpreted as high-skilled or non-routine labor) and generates an ICT-capital-labor composite, and the second labor type is identical to the one used in the production of $r$ intermediate goods and is imperfectly 
substitutable with this composite (this second type of labor can be intepreted as low-skilled or routine labor). Then, intermediate-goods firms decide the share of $r$ labor allocated to the production of $r$ intermediate goods, with the remaining share being used in the production of $i$ intermediate goods as an imperfect substitute with the ICT-capital-labor composite.

\section{Link between Technology-Adoption Costs and Salaried-Firm-Entry Costs Whole-} sale firms that want to use $i$ intermediate goods as inputs must pay a fixed cost $f_{i}$, and only those with an idiosyncratic productivity level above an endogenously-determined threshold do so. Guided by the negative relationship between firms' digital adoption and the cost of salaried-firm creation presented in Figure 1 in Section 2 and for reasons that will become apparent in our quantitative analysis, we assume that $f_{i}$ and $f_{e}$ are related such that $f_{e}=\lambda_{f} f_{i}$, where $\lambda_{f}>1$ is a parameter ${ }^{12}$ As such, any changes in $f_{i}$ also generate changes in $f_{e}$ (and vice versa). As suggested by the discussion of the factors linking digital (and technology) adoption and firm entry in the Introduction, this assumption is both intuitive and plausible: the adoption of digital and ICT-capital technologies (and therefore the cost of doing so) is bound to influence salaried firms' costs of entry by making it easier for firms to comply with the regulatory requirements associated with salaried-firm creation using digital technologies, suggesting that $f_{i}$ and $f_{e}$ are likely to be correlated and change in tandem. 13 At the same time, given that digital technologies are an input in the use of automation technologies, digital adoption not only affects firms' entry costs but also, by itself, increases the susceptibility of adopting automation technologies. Our assumption regarding the link between $f_{i}$ and $f_{e}$ embodies all these features tractably. More broadly, this assumption generates facts that are consistent with the correlations between firm-creation costs, new salaried firm creation, and firms' digital adoption in Figure 1 in Section 2.

Finally, as noted in the model summary, wholesale firms that use $r$ intermediate goods

\footnotetext{
${ }^{12}$ Of note, an equally valid assumption that delivers exactly the same results is $f_{i}=\lambda_{e} f_{e}$, where $0<\lambda_{e}<1$ is a parameter. What ultimately matters is that $f_{e}$ and $f_{i}$ are related.

${ }^{13}$ Of course, the opposite can also be true: the regulatory costs of salaried-firm entry can affect the cost of technology adoption via, for example, the degree of regulatory effectiveness. While we do not have direct cross-country, comparable data on the cost of firms' digital adoption, our DEME sample shows that the correlation between firms' digital adoption and government effectiveness or regulatory quality (both measures obtained from the World Bank Worldwide Governance Indicators) is 0.72 and 0.65 , respectively, and significant at the 1 percent level.
} 
are referred to as $r$ wholesale firms, and analogously, wholesale firms that use $i$ intermediate goods are referred to as $i$ wholesale firms.

\subsubsection{Wholesale Firms}

Evolution of Wholesale Firms There is an unbounded number of potential wholesale entrants. Denoting by $N_{t}$ the measure of active wholesale firms and by $N_{e, t}$ the measure of new wholesale entrants, the evolution of total wholesale firms is

$$
N_{t}=(1-\delta)\left[N_{t-1}+N_{e, t-1}\right]
$$

Given how wholesale firms decide which category of intermediate goods they use, the measure

of $i$ wholesale firms is given by $N_{i, t}=\left[1-G\left(a_{i, t}\right)\right] N_{t}$, where $a_{i, t}$ is the threshold productivity level above which wholesale firms use $i$ intermediate goods.

Wholesale Firm Profits and Threshold Productivity Level If a given wholesale firm $a$ uses $r$ intermediate goods, its profits are given by

$$
d_{r, t}(a)=\left[\rho_{r, t}(a)-\frac{m c_{r, t}}{a}\right] y_{r, t}(a)
$$

where $\rho_{r, t}(a)$ is wholesale firm $a$ 's real price, $m c_{r, t}$ is the price of $r$ intermediate goods, and $y_{r, t}(a)$ is firm $a$ 's output.

If a given wholesale firm $a$ uses $i$ intermediate goods, its profits are given by

$$
d_{i, t}(a)=\left[\rho_{i, t}(a)-\frac{m c_{i, t}}{a}\right] y_{i, t}(a)-f_{i}
$$

where $\rho_{i, t}(a)$ is wholesale firm $a$ 's real price, $m c_{i, t}$ is the price of $i$ intermediate goods, and $y_{i, t}(a)$ is firm $a$ 's output. Then, total profits for firm $a$ are given by $d_{t}(a)=d_{i, t}(a)+d_{r, t}(a)$.

It follows that the condition that pins down the idiosyncratic productivity threshold above which wholesale firms use $i$ intermediate goods, $a_{i, t}$, is $d_{i, t}\left(a_{i, t}\right)=0$. 
Wholesale Firm Optimal Pricing It is straightforward to show that the demand function for wholesale firm $a$ 's output $y_{j, t}(a)$ is $y_{j, t}(a)=\left(\rho_{j, t}(a) / p_{s, t}\right)^{-\varepsilon} Y_{s, t}$ for $j \in\{i, r\}$, where $\varepsilon>1$ is the elasticity of substitution between wholesale output varieties and $p_{s, t}$ is the relative price of aggregate wholesale-firm output $Y_{s, t}$. Then, given the profit functions for wholesale firm $a$ defined above, the optimal real price for firm $a$ using intermediate goods $j \in\{i, r\}$ is

$$
\rho_{j, t}(a)=\frac{\varepsilon}{\varepsilon-1} \frac{m c_{j, t}}{a}
$$

Wholesale-Firm Averages There are two average idiosyncratic productivity levels, one for $r$ wholesale firms, $\widetilde{a}_{s}$, and one for $i$ wholesale firms, $\widetilde{a}_{i, t}$ :

$$
\widetilde{a}_{s}=\left[\int_{a_{\min }}^{\infty} a^{\varepsilon-1} d G(a)\right]^{\frac{1}{\varepsilon-1}}
$$

and

$$
\widetilde{a}_{i, t}=\left[\frac{1}{1-G\left(a_{i, t}\right)}\right]\left[\int_{a_{i, t}}^{\infty} z^{\varepsilon-1} d G(a)\right]^{\frac{1}{\varepsilon-1}} .
$$

Following the macro literature on endogenous firm entry (GM, 2005), we use a Pareto distribution for $G(a)=\left[1-\left(a_{\min } / a\right)^{k_{p}}\right]$ with shape parameter $\varepsilon-1<k_{p}$. Then, these average productivities can be written as

$$
\widetilde{a}_{s}=\left(\frac{k_{p}}{k_{p}-(\varepsilon-1)}\right)^{\frac{1}{\varepsilon-1}} a_{\min },
$$

and

$$
\widetilde{a}_{i, t}=\left(\frac{k_{p}}{k_{p}-(\varepsilon-1)}\right)^{\frac{1}{\varepsilon-1}} a_{i, t} .
$$

Then, we can write the number of $i$ wholesale firms, $N_{i, t}$, as

$$
N_{i, t}=\left(\frac{a_{m i n}}{\widetilde{a}_{i, t}}\right)^{k_{p}}\left(\frac{k_{p}}{k_{p}-(\varepsilon-1)}\right)^{\frac{k_{p}}{\varepsilon-1}} N_{t}
$$


Moreover, average wholesale-firm profits are given by

$$
\widetilde{d}_{t}=\widetilde{d}_{r, t}+\frac{N_{i, t}}{N_{t}} \widetilde{d}_{i, t}
$$

and the condition that pins down $a_{i, t}$ can be expressed as

$$
\widetilde{d}_{i, t}=\left[\frac{\varepsilon-1}{k_{p}-(\varepsilon-1)}\right] f_{i},
$$

where $\widetilde{d}_{r, t} \equiv d_{r, t}\left(\widetilde{a}_{s}\right)$ and $\widetilde{d}_{i, t} \equiv d_{i, t}\left(\widetilde{a}_{i, t}\right)$. Along similar lines, the average prices for $r$ and $i$ wholesale firms are given by $\widetilde{\rho}_{r, t} \equiv \rho_{r, t}\left(\widetilde{a}_{s}\right)$ and $\widetilde{\rho}_{i, t} \equiv \rho_{i, t}\left(\widetilde{a}_{i, t}\right)$, so that the relative price of

aggregate salaried output can be written as $p_{s, t}=\left[N_{t}\left(\widetilde{\rho}_{r, t}\right)^{1-\varepsilon}+N_{i, t}\left(\widetilde{\rho}_{i, t}\right)^{1-\varepsilon}\right]^{\frac{1}{1-\varepsilon}}$. Finally, average salaried wholesale output in each category is given by $\widetilde{y}_{r, t} \equiv y_{r, t}\left(\widetilde{a}_{s}\right)$ and $\widetilde{y}_{i, t} \equiv$ $y_{i, t}\left(\widetilde{a}_{i, t}\right)$.

\subsubsection{Intermediate-Goods Firms}

There is a measure one of perfectly-competitive salaried firms that produce intermediate goods for salaried wholesale firms. In particular, the representative intermediate-goods firm produces two different categories of intermediate goods, $r$ and $i$, using two distinct production technologies. The first technology produces $r$ intermediate goods using only $r$ salaried workers $n_{r, t}^{r}$. The second technology produces $i$ intermediate goods using $i$ salaried workers $n_{i, t}^{i}$, ICT capital $k_{i, t}$, and $r$ salaried workers $n_{r, t}^{i}$, where ICT capital and $i$ labor are used as complements and $r$ salaried labor is imperfectly substitutable with the ICT-capital-i-labor composite. Given this structure, total $r$ salaried employment is $n_{r, t} \equiv n_{r, t}^{r}+n_{r, t}^{i}$.

Firms spend resources to post vacancies $v_{i, t}$ and $v_{r, t}$ to hire new $i$ and $r$ salaried workers, respectively. Once firms hire $r$ workers, they choose how to assign them to one of the two production technologies by choosing the share $\omega_{t}$ of total $r$ salaried employment $n_{r, t}$ allocated to the production of $i$ intermediate goods. Then, it follows that $n_{r, t}^{i}=\omega_{t} n_{r, t}$ and $n_{r, t}^{r}=\left(1-\omega_{t}\right) n_{r, t}$. We use these definitions further below. In contrast, $i$ workers are only used in the production of $i$ intermediate goods alongside ICT capital. Given our assumptions about the relationship between inputs $n_{i, t}^{i}, n_{r, t}^{i}$, and $k_{i, t}$ in the production of $i$ intermediate 
goods, one can interpret $i$ and $r$ workers as skilled/non-routine and unskilled/routine salaried workers, respectively, and the $r$ and $i$ production technologies as the routine and non-routine production technologies, respectively.

Formally, intermediate-goods firms choose vacancies $v_{r, t}$ and $v_{i, t}$, the desired measure of $r$ and $i$ workers $n_{r, t+1}$ and $n_{i, t+1}^{i}$, the fraction $\omega_{t}$ of total $r$ salaried labor $n_{r, t}$ that is allocated to production of $i$ intermediate goods, and accumulate ITC capital $k_{i, t+1}$ to maximize $\mathbb{E}_{0} \sum_{t=0}^{\infty} \Xi_{t \mid 0} \Pi_{s, t}$ subject to

$$
\begin{gathered}
\Pi_{s, t}=\left[m c_{r, t} z_{t} G\left(n_{r, t}^{r}\right)-w_{r, t}^{r} n_{r, t}^{r}-\psi_{r} v_{r, t}\right] \\
+\left[m c_{i, t} z_{t} F\left(n_{r, t}^{i}, n_{i, t}^{i}, k_{i, t}\right)-w_{i, t}^{i} n_{i, t}^{i}-w_{r, t}^{i} n_{r, t}^{i}-\left(k_{i, t+1}-\left(1-\delta_{i}\right) k_{i, t}\right)-\psi_{i} v_{i, t}\right] \\
n_{r, t+1}=\left(1-\rho_{s}\right)\left[n_{r, t}+v_{r, t} q\left(\theta_{r, t}\right)\right], \\
n_{i, t+1}^{i}=\left(1-\rho_{s}\right)\left[n_{i, t}^{i}+v_{i, t} q\left(\theta_{i, t}\right)\right],
\end{gathered}
$$

and the fact that

$$
n_{r, t}^{r}=\left(1-\omega_{t}\right) n_{r, t}
$$

and

$$
n_{r, t}^{i}=\omega_{t} n_{r, t},
$$

where the production functions $G\left(n_{r, t}^{r}\right)$ and $F\left(n_{i, t}^{i}, n_{r, t}^{i}, k_{i, t}\right)$ are constant-returns-to-scale and $z_{t}$ is aggregate productivity. $\psi_{r}$ and $\psi_{i}$ are the flow costs of posting a vacancy for workers who produce $r$ and $i$ intermediate goods, respectively; $w_{r, t}^{r}$ and $w_{r, t}^{i}$ are the real wages of $r$ workers producing $r$ and $i$ intermediate goods, respectively; $w_{i, t}^{i}$ is the real wage of $i$ workers; and $q\left(\theta_{r, t}\right)$ and $q\left(\theta_{i, t}\right)$ are the corresponding job-filling probabilities (which are a function of their respective market tightness $\theta_{r, t}$ and $\theta_{i, t}$, defined further below), all of which are taken as given by firms. Above, $0<\delta_{i}<1$ is the exogenous depreciation rate of ICT capital and $0<\rho_{s}<1$ is the exogenous separation probability of salaried workers.

The first-order conditions yield a standard ICT capital Euler equation

$$
1=\mathbb{E}_{t} \Xi_{t+1 \mid t}\left[r_{i, t+1}+\left(1-\delta_{i}\right)\right]
$$


where $r_{i, t} \equiv m c_{i, t} z_{t} F_{k_{i}, t}$ is the real marginal revenue product of ICT capital; an optimal decision over the allocation of $r$ workers across the production of $r$ and $i$ intermediate goods, $\omega_{t}$, that can be written as 14

$$
m c_{i, t} z_{t} F_{n_{r}^{i}, t}-w_{r, t}^{i}=m c_{r, t} z_{t} G_{n_{r}^{r}, t}-w_{r, t}^{r}
$$

as well as standard job creation conditions for salaried employment in each of the intermediategoods categories

$$
\frac{\psi_{r}}{q\left(\theta_{r, t}\right)}=\left(1-\rho_{s}\right) \mathbb{E}_{t} \Xi_{t+1 \mid t}\left[\begin{array}{c}
\left(1-\omega_{t+1}\right)\left[m c_{r, t+1} z_{t+1} G_{n_{r}^{r}, t+1}-w_{r, t+1}^{r}\right] \\
+\omega_{t+1}\left[m c_{i, t+1} z_{t+1} F_{n_{r}^{i}, t+1}-w_{r, t+1}^{i}\right]+\frac{\psi_{r}}{q\left(\theta_{r, t+1}\right)}
\end{array}\right]
$$

and

$$
\frac{\psi_{i}}{q\left(\theta_{i, t}\right)}=\left(1-\rho_{s}\right) \mathbb{E}_{t} \Xi_{t+1 \mid t}\left[m c_{i, t+1} z_{t+1} F_{n_{i}^{i}, t+1}-w_{i, t+1}^{i}+\frac{\psi_{i}}{q\left(\theta_{i, t+1}\right)}\right] .
$$

The decision over the fraction of $r$ workers assigned to each of the two production technologies is intuitive: firms equate the net real marginal revenue product of labor from allocating an $r$ worker to the production of $r$ intermediate goods to the corresponding net real marginal revenue product of labor from allocating the worker to the production of $i$ intermediate goods. The capital Euler and job creation conditions are standard. Each job creation condition equates the expected marginal cost of posting a vacancy to the expected marginal benefit, where the latter is given by the marginal revenue product of labor net of the real wage and the continuation value of the employment relationship. In the case of the job creation condition for $r$ workers, the expected marginal benefit of posting a vacancy is given by the weighted average of the marginal revenue product of labor net of the wage for the two categories of $r$ workers, where the weights are optimally chosen when, once matched, firms allocate $r$ workers across the two production technologies.

\footnotetext{
${ }^{14}$ To obtain the following condition, note that both $n_{r, t}^{r}=\left(1-\omega_{t}\right) n_{r, t}$ and $n_{r, t}^{i}=\omega_{t} n_{r, t}$ are expressions that intermediate-goods firms explicitly take into account when optimally choosing how to allocate $r$ workers across the two production technologies.
} 


\subsection{Households and Self-Employed Firms}

A representative household chooses consumption $c_{t}$; the measure of household members who search for: self-employment $s_{e, t}$, salaried employment in the $r$ category $s_{r, t}$, and salaried employment in the production in the $i$ category $s_{i, t}$; and the desired measure of individuals in self-employment $n_{e, t+1}, i$ salaried employment $n_{i, t+1}^{i}$, and total $r$ salaried employment $n_{r, t+1}$, to maximize $\mathbb{E}_{0} \sum_{t=0}^{\infty} \beta^{t}\left[\mathbf{u}\left(c_{t}\right)-\mathbf{h}\left(l f p_{e, t}, l f p_{i, t}, l f p_{r, t}\right)\right]$, subject to the budget constraint

$$
c_{t}+f_{e} N_{e, t}+f_{i} N_{i, t}=w_{i, t}^{i} n_{i, t}^{i}+w_{r, t}^{r} n_{r, t}^{r}+w_{r, t}^{i} n_{r, t}^{i}+\widetilde{d}_{t} N_{t}+p_{e, t} z_{t} n_{e, t}+\Pi_{s, t}+\Pi_{y, t},
$$

the evolution of total salaried employment in each category $j \in\{i, r\}$

$$
n_{j, t+1}=\left(1-\rho_{s}\right)\left[n_{j, t}+s_{j, t} f\left(\theta_{j, t}\right)\right],
$$

the evolution of self-employment

$$
n_{e, t+1}=\left(1-\rho_{e}\right)\left[n_{e, t}+s_{e, t} \phi_{e}\right]
$$

the evolution of salaried wholesale firms

$$
N_{t+1}=(1-\delta)\left[N_{t}+N_{e, t}\right]
$$

considering the fact that

$$
n_{r, t}^{r}=\left(1-\omega_{t}\right) n_{r, t}
$$

and

$$
n_{r, t}^{i}=\omega_{t} n_{r, t}
$$

where $l f p_{e, t}=n_{e, t}+s_{e, t}, l f p_{i, t}=n_{i, t}^{i}+s_{i, t}$, and $l f p_{r, t}=n_{r, t}+s_{r, t}$, represent sectoral labor force participation, $\mathbf{u}\left(c_{t}\right)$ is increasing and concave, and $\mathbf{h}\left(l f p_{e, t}, l f p_{i, t}, l f p_{r, t}\right)$ is increasing and convex in $l f p_{j, t}$ for $j \in\{e, i, r\}$. Note that households choose desired total $r$ salaried employment $n_{r, t+1}$ but recognize that, once matched, intermediate-goods firms can assign $r$ workers to one of the two production technologies and take firms' allocation decisions (i.e., 
firms' choice over $\omega_{t}$ ) as given. In the household's budget constraint, $\widetilde{d}_{t} N_{t}$ are total average profits from salaried wholesale firms; $p_{e, t} z_{t} n_{e, t}$ are total real profits from self-employed firms, where total self-employment production is $Y_{e, t}=z_{t} n_{e, t} ; \Pi_{s, t}$ are lump-sum real profits from salaried intermediate-goods firms; and $\Pi_{y, t}$ are lump-sum real profits from final goods firms. Turning to the perceived evolution of employment, $\rho_{e}$ is the exogenous separation probability of self-employed individuals, $\phi_{e}$ is a scaling parameter that embodies the efficiency with which individuals search for self-employment opportunities, and $f\left(\theta_{r, t}\right)$ and $f\left(\theta_{i, t}\right)$ are the salaried job-finding probabilities, which the household takes as given.

The first-order conditions yield a salaried-wholesale-firm creation condition

$$
f_{e}=(1-\delta) \mathbb{E}_{t} \Xi_{t+1 \mid t}\left[\widetilde{d}_{t+1}+f_{e}\right],
$$

two participation decisions for $r$ and $i$ salaried workers

$$
\frac{\mathbf{h}_{l f p_{r, t}}}{\mathbf{u}^{\prime}\left(c_{t}\right)} \frac{1}{f\left(\theta_{r, t}\right)}=\left(1-\rho_{s}\right) \mathbb{E}_{t} \Xi_{t+1 \mid t}\left[w_{r, t+1}^{r}\left(1-\omega_{t+1}\right)+w_{r, t+1}^{i} \omega_{t+1}+\left(\frac{1}{f\left(\theta_{r, t+1}\right)}-1\right) \frac{\mathbf{h}_{l f p_{r, t+1}}}{\mathbf{u}^{\prime}\left(c_{t+1}\right)}\right],
$$

and

$$
\frac{\mathbf{h}_{l f p_{i, t}}}{\mathbf{u}^{\prime}\left(c_{t}\right)} \frac{1}{f\left(\theta_{i, t}\right)}=\left(1-\rho_{s}\right) \mathbb{E}_{t} \Xi_{t+1 \mid t}\left[w_{i, t+1}^{i}+\left(\frac{1}{f\left(\theta_{i, t+1}\right)}-1\right) \frac{\mathbf{h}_{l f p_{i, t+1}}}{\mathbf{u}^{\prime}\left(c_{t+1}\right)}\right],
$$

and a participation decision for self-employment

$$
\frac{\mathbf{h}_{l f p_{e, t}}}{\mathbf{u}^{\prime}\left(c_{t}\right)} \frac{1}{\phi_{e}}=\left(1-\rho_{e}\right) \mathbb{E}_{t} \Xi_{t+1 \mid t}\left[p_{e, t+1} z_{t+1}+\left(\frac{1}{\phi_{e}}-1\right) \frac{\mathbf{h}_{l f p_{e, t+1}}}{\mathbf{u}^{\prime}\left(c_{t+1}\right)}\right],
$$

where $\Xi_{t+1 \mid t}=\beta \mathbf{u}^{\prime}\left(c_{t+1}\right) / \mathbf{u}^{\prime}\left(c_{t}\right)$ is the household's stochastic discount factor. Intuitively, households equate the marginal cost of creating a new salaried wholesale firm to the expected marginal benefit. The latter is given by the expected average individual-firm profits and the continuation value if the firm remains in operation next period. In terms of optimal labor force participation decisions, households equate the expected marginal cost of sending one more household member to search for $r$ or $i$ salaried employment to the expected marginal benefit, where the choice to send household members to search for $r$ salaried employment is influenced by salaried firms' allocation of $r$ salaried employment to the production of 
$r$ or $i$ intermediate goods - that is, firms' choice over $\omega_{t}$-which households recognize as

a firms' choice but take it as given when making participation decisions. From a general standpoint, the marginal benefit of salaried participation is given by the expected discounted real wage and the continuation value of having a household member remain a worker net of the utility cost from participating as a salaried worker in each salaried employment category. Analogously, households equate the marginal cost of becoming self-employed to the expected marginal benefit. The latter is given by the marginal product of a self-employed individual and the continuation value net of the utility cost from participating in the labor market as a self-employed individual.

Since the total population in the economy is normalized to one, the total labor force participation rate is $l f p_{t}=l f p_{e, t}+l f p_{i, t}+l f p_{r, t}$. Then, we can define the (economy-wide) unemployment rate is $u r_{t} \equiv\left(s_{e, t}+s_{i, t}+s_{r, t}\right) / l f p_{t}$.

\subsection{Matching Processes and Wage Determination}

Following the search and matching literature, the matching functions for the two categories of salaried employment $r$ and $i, m\left(s_{r, t}, v_{r, t}\right)$ and $m\left(s_{i, t}, v_{i, t}\right)$, respectively, are constant-returnsto-scale and take as arguments the salaried searchers and vacancies for their respective categories. Then, for salaried employment category $j \in\{r, i\}$, the job-finding and job-filling probabilities are given by $f\left(\theta_{j, t}\right)=m\left(s_{j, t}, v_{j, t}\right) / s_{j, t}$ and $q\left(\theta_{j, t}\right)=m\left(s_{j, t}, v_{j, t}\right) / v_{j, t}$, respectively, where market tightness $\theta_{j, t}=v_{j, t} / s_{j, t}$.

Wages are determined as the outcome of a bilateral Nash bargaining process between firms and salaried workers. The household's net values of having an $r$ worker produce $r$ intermediate goods, an $r$ worker produce $i$ intermediate goods, and an $i$ worker produce $i$ intermediate goods are given by

$$
\begin{aligned}
& \mathbf{W}_{r, t}^{r}=w_{r, t}^{r}-\frac{\mathbf{h}^{\prime}\left(l f p_{r, t}\right)}{\mathbf{u}^{\prime}\left(c_{t}\right)}+\left(1-\rho_{s}\right) \mathbb{E}_{t} \Xi_{t+1 \mid t} \mathbf{W}_{r, t+1}^{r}, \\
& \mathbf{W}_{r, t}^{i}=w_{r, t}^{i}-\frac{\mathbf{h}^{\prime}\left(l f p_{r, t}\right)}{\mathbf{u}^{\prime}\left(c_{t}\right)}+\left(1-\rho_{s}\right) \mathbb{E}_{t} \Xi_{t+1 \mid t} \mathbf{W}_{r, t+1}^{i},
\end{aligned}
$$


and

$$
\mathbf{W}_{i, t}^{i}=w_{i, t}^{i}-\frac{\mathbf{h}^{\prime}\left(l f p_{i, t}\right)}{\mathbf{u}^{\prime}\left(c_{t}\right)}+\left(1-\rho_{s}\right) \mathbb{E}_{t} \Xi_{t+1 \mid t} \mathbf{W}_{i, t+1}^{i},
$$

respectively. The corresponding values to intermediate-goods firms of having each of these workers is

$$
\begin{aligned}
& \mathbf{J}_{r, t}^{r}=m c_{r, t} z_{t} G_{n_{r, t}^{r}}-w_{r, t}^{r}+\left(1-\rho_{s}\right) \mathbb{E}_{t} \Xi_{t+1 \mid t} \mathbf{J}_{r, t+1}^{r}, \\
& \mathbf{J}_{r, t}^{i}=m c_{i, t} z_{t} F_{n_{r, t}^{i}}-w_{r, t}^{i}+\left(1-\rho_{s}\right) \mathbb{E}_{t} \Xi_{t+1 \mid t} \mathbf{J}_{r, t+1}^{i},
\end{aligned}
$$

and

$$
\mathbf{J}_{i, t}^{i}=m c_{i, t} z_{t} F_{n_{i, t}^{i}}-w_{i, t}^{i}+\left(1-\rho_{s}\right) \mathbb{E}_{t} \Xi_{t+1 \mid t} \mathbf{J}_{i, t+1} .
$$

Then, denoting by $0<\nu<1$ the bargaining power of workers, the Nash wages for each type

of salaried employment are implicitly given by $(1-\nu) \mathbf{W}_{r, t}^{r}=\nu \mathbf{J}_{r, t}^{r},(1-\nu) \mathbf{W}_{r, t}^{i}=\nu \mathbf{J}_{r, t}^{i}$, and $(1-\nu) \mathbf{W}_{i, t}^{i}=\nu \mathbf{J}_{i, t}^{i}$.

\subsection{Symmetric Equilibrium and Market Clearing}

Output produced by salaried intermediate-goods firms with the $r$ production technology must be equal to total output by salaried wholesale firms who use $r$ intermediate goods:

$$
z_{t} G\left(n_{r, t}^{r}\right)=N_{t}\left(\frac{\widetilde{y}_{r, t}}{\widetilde{a}_{s}}\right),
$$

Analogously, output produced by salaried intermediate-goods firms with the $i$ production technology must be equal to total output by salaried wholesale firms who use $i$ intermediate goods:

$$
z_{t} F\left(n_{r, t}^{i}, n_{i, t}^{i}, k_{i, t}\right)=N_{i, t}\left(\frac{\widetilde{y}_{i, t}}{\widetilde{a}_{i, t}}\right)
$$

Finally, the resource constraint of the economy is given by

$$
Y_{t}=c_{t}+\left(k_{i, t+1}-\left(1-\delta_{i}\right) k_{i, t}\right)+\psi_{r} v_{r, t}+\psi_{i} v_{i, t}+f_{e} N_{e, t}+f_{i} N_{i, t}
$$

Appendix A.3 presents the complete list of equilibrium conditions. 


\subsection{Business Digital Adoption Index: Mapping Between the Data and the Model}

Recall from Section 2 that we use the World Bank's Business Digital Adoption Index (BDAI) as a proxy of firms' technology adoption, which we consider to be labor-replacing for a segment of workers. Also, per Section 2, this index has a scale from 0 to 1, with 1 capturing full digital adoption based on the four indicators that comprise the BDAI. In our theoretical framework, $N_{i} / N$ represents the share of firms that use inputs produced with the ICT-capital production technology, i.e. the share of $i$ firms in the universe of salaried firms. Moreover, this share is between 0 and 1 under plausible parameterizations. Given these facts and absent explicit data on the share of firms that have adopted digital/automation technologies, for the purposes of our quantitative analysis, we consider $N_{i} / N$ as the model counterpart of the BDAI.

\section{Quantitative Analysis}

\subsection{Calibration and Operationalization}

Utility over consumption is of the CRRA form and disutility from labor force participation is convex: $\mathbf{u}\left(c_{t}\right)-\mathbf{h}\left(l f p_{e, t}, l f p_{i, t}, l f p_{r, t}\right)=\frac{c_{t}^{1-\sigma_{c}}}{1-\sigma_{c}}-\left[\frac{\left(\kappa_{e}\left(l f p_{e, t}\right)+\kappa_{i}\left(l f p_{i, t}\right)+\kappa_{r}\left(l f p_{r, t}\right)\right)^{1+\frac{1}{\chi}}}{1+\frac{1}{\chi}}\right]$, where $\sigma_{c}, \kappa_{e}, \kappa_{i}, \kappa_{r}, \chi>0$. The production of $r$ intermediate goods is linear in the allocated amount of $r$ salaried labor: $G\left(n_{r, t}^{r}\right)=n_{r, t}^{r}$ and production of $i$ intermediate goods is a CES aggregator of $r$ salaried labor allocated to the $i$ technology, $n_{r, t}^{i}$, and a CES composite of ITC capital and $i$ salaried labor $n_{i, t}^{i}: F\left(n_{i, t}^{i}, n_{r, t}^{i}, k_{i, t}\right)=\left[\left(1-\phi_{i}\right)\left(n_{r, t}^{i}\right)^{\lambda_{i}}+\phi_{i}\left[\alpha_{k} k_{i, t}^{\lambda_{k}}+\left(1-\alpha_{k}\right)\left(n_{i, t}^{i}\right)^{\lambda_{k}}\right]^{\lambda_{i} / \lambda_{k}}\right]^{1 / \lambda_{i}}$ where $0<\phi_{i}, \alpha_{k}<1$ and $\lambda_{i}, \lambda_{k}<1$. Following den Haan, Ramey, and Watson (2000), the salaried matching function is $m\left(s_{j, t}, v_{j, t}\right)=s_{j, t} v_{j, t} /\left[s_{j, t}^{\xi}+v_{j, t}^{\xi}\right]^{1 / \xi}$, for $j \in\{i, r\}$, where $\xi>0$ (this specific functional form guarantees that the matching probabilities are bounded between 0 and 1$)$.

Parameters from Literature A period is a quarter. Following the literature on DEMEs, we set the risk aversion parameter $\sigma_{c}=2$, the subjective discount factor $\beta=0.985$, and 
the depreciation rate $\delta_{i}=0.025$ (alternative values for $\delta_{i}$ do not change our main findings). We initially set the elasticity of substitution between salaried wholesale output categories to $\varepsilon=6$, the firm exit rate to $\delta=0.025$, and $k_{p}=5.5$, which satisfies $\varepsilon-1<k_{p}$ and is consistent with the macro literature on endogenous firm entry. As is standard in labor search models, the worker bargaining power is $\nu=0.5$. Without loss of generality, we set the minimum level of idiosyncratic productivity among salaried wholesale firms to $a_{m i n}=1$ (a standard assumption in models of endogenous firm entry and idiosyncratic productivity cutoffs; see GM, 2005), and normalize aggregate productivity $z=1$. Using existing evidence on salaried employment and self-employment separation rates in DEMEs, we set $\rho_{e}=0.03$ and $\rho_{s}=0.05$ (Bosch and Maloney, 2008). We set $\phi_{y}=5$, which implies a relatively high degree of substitutability between salaried-firm and self-employed-firm output ${ }^{15}$ As a baseline and due to limited data availability for DEMEs, we adopt existing estimates for the elasticity of substitution between the two types of salaried labor and ICT capital from Eden and Gaagl (2017) and set $\lambda_{k}=0.3, \lambda_{i}=0.9$, and $\phi_{i}=0.47$.

Estimated values for the elasticity of labor supply on the extensive margin - that is, the elasticity of labor force participation - are based solely on salaried workers and vary widely in the literature. Based on micro-level evidence summarized in Chetty et al. (2011, 2013), we set the extensive-margin elasticity of labor supply to $\chi=0.26{ }^{16}$

Calibrated Parameters and Operationalization Our objective is to shed light on the empirical relationship between firms' digital adoption, self-employment, and unemployment from a quantitative standpoint-more specifically, our focus is on the slopes for selfemployment and unemployment rates as shown in the lower two subpanels of Figure 1 in Section 2. Our calibration strategy is in this spirit.

\footnotetext{
${ }^{15}$ Data from the World Bank Enterprise Surveys for our DEME sample shows that 55 percent of firms compete against unregistered firms, where the latter are primarily self-employed and micro firms. In fact, at least 40 percent of economies in our sample have more than 65 percent of firms stating that they face competition from their unregistered counterparts. The assumption of high substitutability between output categories is consistent with this fact.

${ }^{16}$ Chetty et al. $(2011,2013)$ suggest that micro-based elasticities are around 0.25-0.28. Fiorito and Zanella (2012) argue that macro elasticities lie in the 0.8-1.4 range; Cairo, Fujita, and Morales-Jiménez (2019) suggest that 2.3 is a common value in the macro literature; and Chang et al. (2018) adopt a value closer to 1 based on Rogerson and Wallenius (2014, 2016). Importantly, adopting an elasticity of participation that is higher compared to our baseline value, and therefore closer to those in these other studies, would make our quantitative results stronger and closer to the data.
} 
We consider the economy with the lowest Business Digital Adoption Index (BDAI) in the country sample in Section 2, mainly a BDAI of 0.20, as our baseline economy. Recalling from Section 3 that the model counterpart of the BDAI is $N_{i} / N$, we then use $N_{i} / N=0.20$ as a calibration target. As a baseline, we assume that the flow cost of posting salaried vacancies is the same for the two salaried employment categories $\left(i\right.$ and $r$ ), $\psi_{i}=\psi_{r}=\psi$ (asymmetries in costs do not change our findings). Given our target for $N_{i} / N$ of 0.20 , we calibrate the remaining parameters $\alpha_{k}, \xi, \kappa_{e}, \kappa_{i}, \kappa_{r}, \phi_{e}, \psi, f_{e}$, and $\lambda_{f}$ such that our model replicates: (1) the intercept of the linear trend lines (and not the slopes, which are the endogenous objects we are interested in) that arise from plotting (a) the cost of starting a salaried firm, (b) the self-employment rate, and (c) the unemployment rate against BDAI per Figure 1 in Section 2; (2) an average share of ICT capital compensation in GDP of 0.04 in our country sample (per the Conference Board's Total Economy Database) over the BDAI range; (3) a labor force participation rate that corresponds to the estimated participation rate in an economy with a BDAI of 0.20 in our country sample (World Bank World Development Indicators); (4) a share of $i$ salaried employment in total employment of 0.3 percent, which corresponds to the estimated share of employment with tertiary education - a proxy for employment that complements ICT capital in production - in an economy with a BDAI of 0.20 in our country sample (World Development Indicators); and (5) total vacancy posting costs of roughly 1 percent of output (consistent with related literature for DEMEs; see, for example, Boz et al., 2015). The resulting parameter values are $\alpha_{k}=0.2105, \xi=0.3456, \kappa_{e}=1.0824, \kappa_{i}=$ $2.6802, \kappa_{r}=1.7641, \phi_{e}=0.50, \psi=0.0639, f_{i}=0.0013$, and $\lambda_{f}=576.8259$. Since per Section 3 the fixed cost of technology adoption $f_{i}$ and the sunk entry cost of creating salaried firms are directly related via $f_{e}=\lambda_{f} f_{i}$ with $\lambda_{f}>1$, we obtain $f_{e}=0.7462$. Recall, then, that changes in $f_{i}$ are directly reflected in changes in $f_{e}$ (and vice versa).

To trace out the empirical range of firms' digital adoption (BDAI) in our DEME sample and per the evidence on firm-creation costs, new firm density, and digital adoption in Figure 1 of Section 2, we reduce the fixed cost of technology adoption $f_{i}$ from its baseline value so as to generate a range of $N_{i} / N$ from 0.20 to 0.80 , (the empirical range for BDAI in our sample). Of course, given the link between $f_{i}$ and $f_{e}$ we assume following the evidence on BDAI and firm creation costs in Figure 1, $f_{e}$ falls accordingly as well. We stress that, given 
this relationship between costs, there is nothing special about reducing $f_{i}$ versus reducing $f_{e}$ : reducing $f_{e}$ instead would yield exactly the same outcomes we discuss below as long as $f_{i}$ also falls. Given this fact, we discuss our results below within the context of a reduction in $f_{i}$

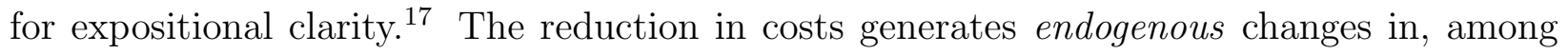
other things, the creation of firms and employment and the allocation of employment across categories. This exercise generates unique pairings between $N_{i} / N$ and the other endogenous variables in the model for each value of $f_{i}$ (and hence $f_{e}$ ). This exercise allows us to examine the extent to which our model can trace out the empirical relationship between digital adoption, self-employment rates, and unemployment rates.

\subsection{Digital Adoption and Labor Markets: Data vs. Model}

Figure 3 summarizes the outcome of this experiment by plotting the same model-generated relationships between firms' digital adoption, the cost of creating a salaried firm (as a share of income), the self-employment rate, and the unemployment rate against the corresponding empirical patterns in Figure 1.

As Figure 3 suggests, under a disciplined calibration, our model can successfully generate the quantitative relationship between digital adoption, self-employment rates, and unemployment rates in DEMEs quite well. For completeness, Figure A1 in the Appendix shows that our model successfully captures the quantitative relationship between BDAI and new firm density in the data without this link between targeted, which lends further credence to our framework. Of note, the model-based reduction in the cost of creating a firm (as a share of income per capita), $f_{e} / Y$, as digital adoption increases is driven by both the reduction in $f_{e}$ itself (which traces back to the reduction in $f_{i}$ ) as well as a non-trivial increase in total output $Y$ (see bottom left panel of Figure A9 in the Appendix). We note that the positive link between digital adoption and output in our framework is consistent with the strong and

\footnotetext{
${ }^{17}$ Also, since $f_{e}$ is an explicit function of $f_{i}$ per our assumption, we are effectively changing a single parameter that not only appears in the optimal salaried-firm technology-adoption condition, but also in the optimal salaried firm creation condition, and analyzing how the steady state changes holding all other parameters at their baseline values. Of course, changing other parameters alongside $f_{i}$ (and $f_{e}$ ) would potentially generate dispersion in the relationship between $N_{i} / N$ and the variables we are interested in (selfemployment and unemployment) for each value of $N_{i} / N$. However, this particular experiment would cloud the economic mechanisms in the model.
} 
positive relationship between digital adoption by firms and GDP documented in World Bank (2016).

Figure 3: Firms' Digital Adoption and Labor Market Outcomes: Data vs. Model
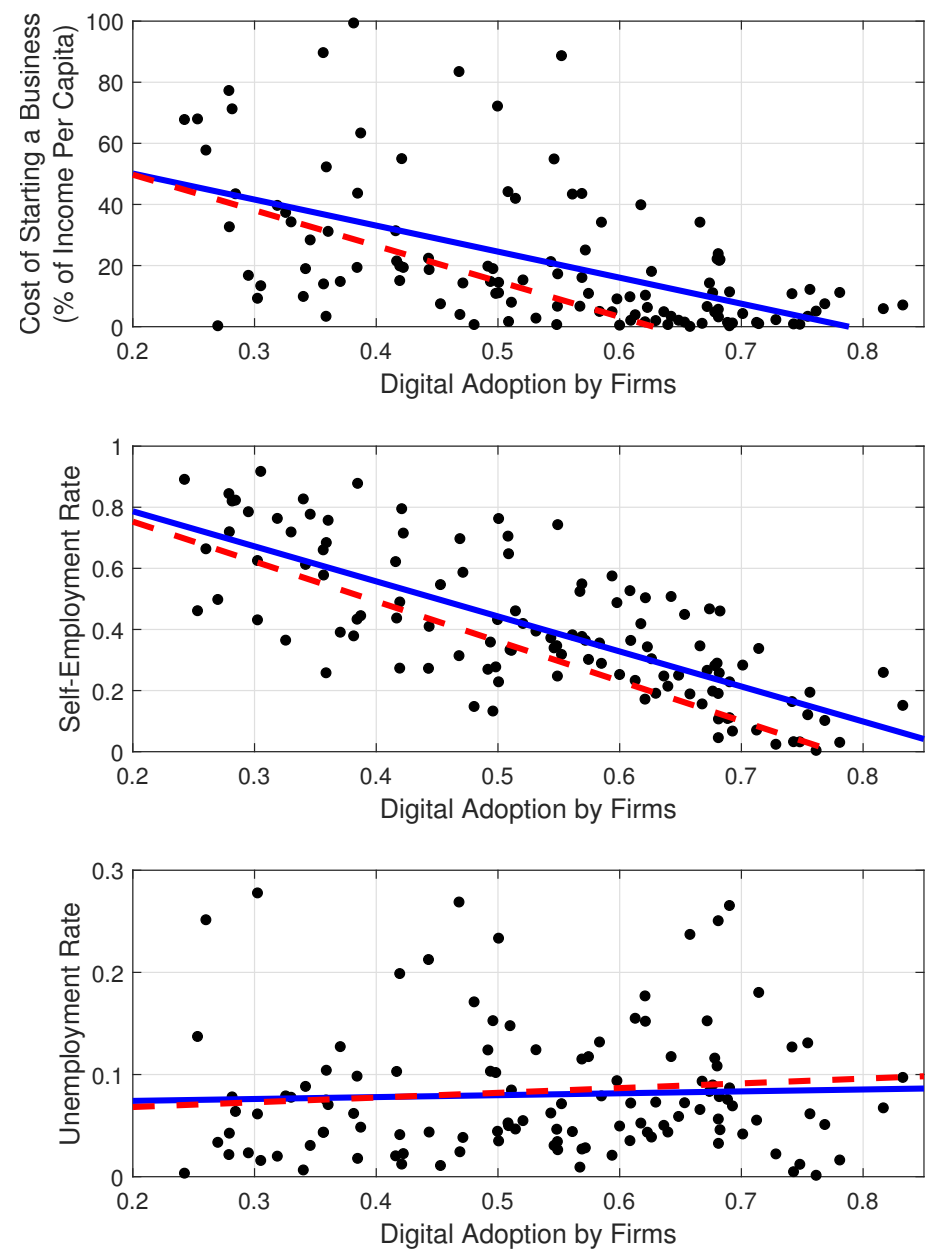

- Data $\longrightarrow$ Data: Linear Trend $-\quad-$ Model: Linear Trend

\subsection{Economic Mechanisms}

To shed light on the economic mechanisms behind Figure 3 , Figure 4 plots the steady state of select model variables as we vary $N_{i} / N$ over its empirical range as described in the operationalization of the model. As the cost of technology adoption (and therefore the 
salaried-firm sunk entry cost) falls, more salaried firms $(N)$ enter the market, and a greater share of those firms source inputs from the ICT-capital technology (that is, $N_{i}$ increases at a faster pace than $N$; see the last two bottom subpanels of Figure 44. Greater salariedfirm creation and more salaried firms using inputs from the ICT-capital technology not only bolsters demand for ICT capital and increases ICT capital accumulation, but also raises salaried firms' value of having salaried workers $\left(\mathbf{J}_{i}\right.$ and $\left.\mathbf{J}_{r, t}^{r}\right){ }^{18}$ This leads to an increase in vacancy postings in both salaried-firm categories $\left(v_{i}\right.$ and $\left.v_{r}\right)$. The increase in vacancy postings attracts salaried searchers $\left(s_{i}\right.$ and $\left.s_{r}\right)$, which is reflected in an increase in the share of individuals that search for salaried jobs, and in a change in the composition of unemployment away from self-employment searchers and towards salaried searchers in both salaried categories.

The increase in vacancies is greater than the increase in salaried searchers, which is reflected in an increase in salaried job-finding probabilities across the board. All told, $i$ and $r$ salaried employment $\left(n_{i}, n_{r}^{r}\right.$, and $n_{r}^{i}$ all divided by the labor force $\left.L F P\right)$ increase, with the increase in $r$ employment in $r$ firms being much greater (first upper subpanel of Figure 44. Moreover, the reallocation of searchers towards salaried employment amid greater salaried-firm entry generates significant downward pressure on self-employment, resulting in large reductions in self-employment rates $\left(n_{e} / L F P\right)$ that are quantitatively consistent with the data. Also, for there to be a trivial (or non-significant) increase in unemployment as in the data, the increase in vacancy postings by salaried firms must be large enough to attract a significant number of searchers and create enough salaried employment to offset the fall in self-employment. This is indeed the case in the model.

\footnotetext{
${ }^{18} \mathbf{J}_{r, t}^{i}$ and $\mathbf{J}_{r, t}^{r}$ behave in the same way; as such, we only present one of them.
} 
Figure 4: ICT-Capital Technology Adoption and Steady-State Equilibria: Benchmark Model
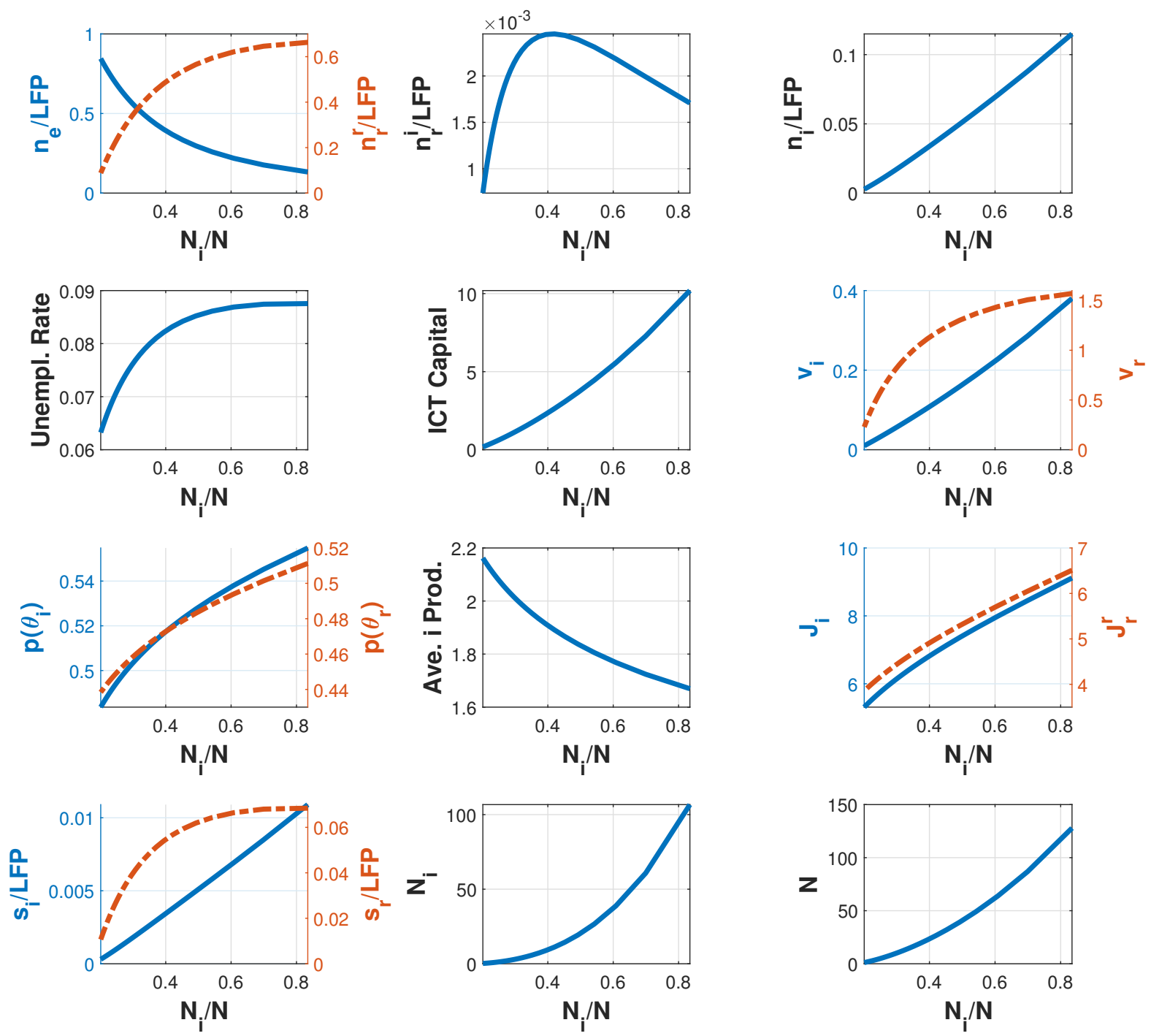

Two outcomes in Figure 4 are worth highlighting. First, the bulk of the increase in total salaried employment as digital adoption increases - which is critical for understanding the relatively small (and quantitatively factual) changes in the unemployment rate - is observed in $r$ salaried employment as opposed to $i$ salaried employment. Second, despite the expansion of firms that rely on the ICT-capital technology for inputs, there is little reallocation of $r$ 
salaried employment away from $r$ firms and into $i$ firms (that is, the share of $n_{r}^{i}$ in the labor force does not change much). In fact, the bulk of the adjustment by $i$ firms to lower fixed and sunk-entry costs takes place via greater ICT capital usage and less so via $i$ salaried employment. This implies that the small, empirically-consistent increase in unemployment (from roughly 6.8 percent to 9.6 percent over the BDAI range) is limited by the rise in $r$ salaried employment and less so by the rise in $i$ salaried employment as self-employment is drastically reduced.

Before delving deeper into the model's mechanisms, we note that the existing literature on automation and labor markets in advanced economies (AEs) generally focuses on how routine jobs are impacted by automation exposure. Our work goes beyond routine employment alone and instead considers two important employment categories in DEMEs: salaried work and self-employment. Of course, a fraction of employment in these two categories may very well be comprised of routine jobs or jobs that are more susceptible to automation amid greater digital adoption. Given the nature of self-employment in DEMEs - which tends to be unskilled, primarily in services and retail trade, and likely to be more exposed to routinization - a simple metric of routine jobs in our model is given by the share of selfemployment and $r$ salaried employment in total employment (that is, $\left.\left(n_{e}+n_{r}\right) /\left(n_{e}+n_{r}+n_{i}\right)\right)$. In our model, this share is monotonically decreasing in the model measure of digital adoption, $N_{i} / N$ (specifically, this share falls by more than 12 percentage points over the BDAI range) ${ }^{19}$ Therefore, our model findings are broadly consistent with a reduction in routine jobs as digital adoption increases. Moreover, in the data, greater digital adoption is associated with greater levels of GDP per capita (World Bank, 2016), and in turn greater levels of GDP per capita are associated with greater salaried-employment shares (Poschke, 2018). Our model is able to replicate these facts as well.

The Importance of New Salaried Firm Creation To better understand the model mechanisms underlying the results in Figure 3, we consider a modified version of the model where salaried firms' fixed costs of accessing the ICT-capital production technology $\left(f_{i}\right)$ and sunk entry costs $\left(f_{e}\right)$ are independent of each other (recall that in the benchmark model,

\footnotetext{
${ }^{19}$ Using $\left(n_{e}+n_{r}^{i}\right) /\left(n_{e}+n_{r}+n_{i}\right)$ as an alternative metric of routine jobs yields very similar results.
} 
$f_{e}=\lambda_{f} f_{i}$ with $\left.\lambda_{f}>1\right)$. Given this separation in costs, we reduce $f_{i}$ to generate the range in firms' digital adoption in our DEME sample while keeping $f_{e}$ constant and unchanged at its baseline value. Figure 5 shows results for this experiment 20

Figure 5: ICT-Capital Technology Adoption and Labor Market Outcomes: Data vs. Model, No Change in $f_{e}$
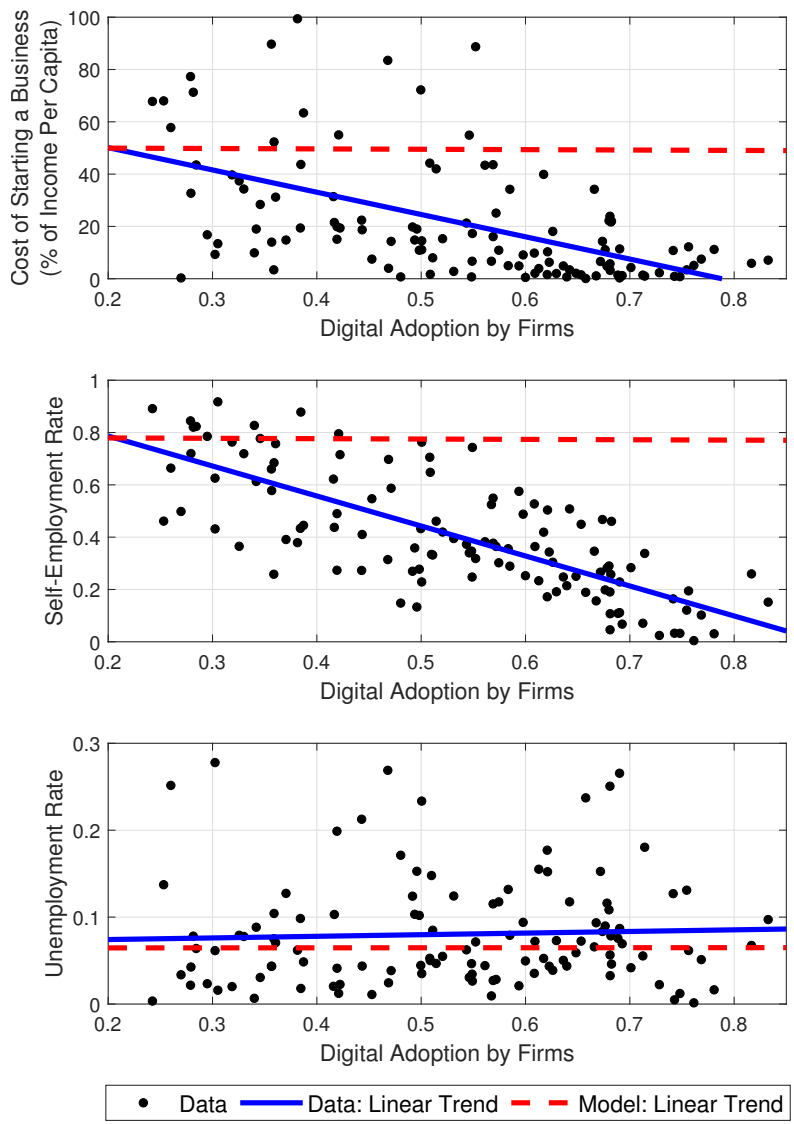

\footnotetext{
${ }^{20}$ For comparability with our baseline results, this experiment adopts the same calibrated parameter values as those in our benchmark model-implying that the baseline-economy steady states of the two models are the same -instead of recalibrating the model under a scenario where $f_{i}$ and $f_{e}$ are independent of each other. Recalibrating this last model and changing $f_{i}$ only so as to generate the range of digital adoption in the data does not change the findings in Figure 5. A third plausible experiment would be to change $f_{e}$ so as to generate the empirical range in the BDAI while holding $f_{i}$ constant and unchanged at its baseline level. Importantly, generating an increase in $N_{i} / N$ from the baseline value of 0.20 to 0.80 by only changing $f_{e}$ requires increasing $f_{e}$ (otherwise, a reduction in $f_{e}$ would reduce $N_{i} / N$ by increasing $N$ more than $N_{i}$ ). Given the evidence on firm-creation costs and digital adoption in Figure 1 in Section 2, the outcome from this experiment is inconsistent with the data. We therefore abstain from discussing this case.
} 
Intuitively, a reduction in the fixed cost of adopting the ICT-capital technology $f_{i}$ alone holding the salaried sunk entry cost $f_{e}$ at its baseline value increases $N_{i} / N$ but is not powerful enough to generate a large-enough reallocation of employment away from self-employment and into salaried employment because the base that ultimately supports salaried employment in the economy - the number of salaried firms $N$-remains largely unchanged absent changes to $f_{e}$ alongside reductions in $f_{i}$. As a result, total output also exhibits negligible changes (see lower right panel in Figure A9 in the Appendix, which shows that the quantitative change in output is minimal). Then, if the change in $N$ is negligible (as confirmed in Figure A7), there is little incentive for firms to increase vacancy postings drastically in response to a lower $f_{i}$ only. Hence the small quantitative changes in the composition of the labor market and in unemployment. The fact that neither $N_{e}$ nor $N$ change much when the salaried-firm sunk entry cost $f_{e}$ is held constant at its baseline value while the fixed cost of technology adoption $f_{i}$ is lowered is not surprising: doing so effectively holds the stock of salaried firms constant but changes the share of active salaried firms that use ICT-capital inputs ${ }^{21}$

All told, Figure 5 confirms the relevance of the relationship between the cost of technology adoption and the regulatory costs of salaried-firm creation and the resuling impact of this relationship on salaried-firm creation for successfully replicating the relationship between firms' digital adoption, self-employment, and unemployment rates in these economies.

Testable Implications of Model Mechanisms and Empirical Corroboration Our analysis sheds light on the factors behind the link between self-employment, unemployment, and firms' digital adoption in the data and suggests the following testable implication: holding constant total output $Y$ and $N_{e}$ (and hence $N$ ), there is no relationship between self-employment rates and digital adoption by firms.

To see whether this model-based outcome is present in the data, we first revisit the link between self-employment rates and firms' digital adoption in our DEME sample. As a first pass, Figure A10 in the Appendix shows the relationship between our two variables of

\footnotetext{
${ }^{21}$ For completeness, Figure A7 in the Appendix shows the counterpart of Figure 4 for the version of the model where $f_{e}$ and $f_{i}$ are independent of each other. The figure shows that, while the steady-state changes are qualitatively identical to those in our benchmark model, the quantitative changes in all variablesincluding $N_{i}$ and $N$-are all negligible, especially once we consider the non-trivial quantitative change in the rate of firms' digital adoption from 0.20 to 0.80 in the data.
} 
interest based on an exponential (as opposed to linear) fit, which provides a more accurate link between self-employment rates and firms' digital adoption. In particular, the figure reveals that the bulk of the reduction in self-employment rates as BDAI increases occurs in a BDAI range between 0.30 and 0.70 (in fact, a more formal analysis confirms that there is no relationship between self-employment rates and firms' digital adoption if we restrict our DEME sample to a BDAI below 0.30 or above 0.70 ). More formally, the 0.30-0.70 BDAI range corresponds to a DEME subsample comprised of economies that have a BDAI between the 15th and 85th percentiles of our baseline sample: this subrange delivers a DEME sample with a BDAI that lies within one standard deviation of the baseline-DEME-sample mean and includes roughly 70 percent of all DEMEs in our baseline sample (more specifically, this corresponds to a DEME subsample with a BDAI between 0.344 and 0.685).

Table 3: Self-Employment Rates and Business Digital Adoption, New Firm Density and Firm Entry Costs, and the Level of Development

\begin{tabular}{lcccc}
\hline \hline Dep. Var.: Self-Empl. Rate & $(1)$ & $(2)$ & $(3)$ & $(4)$ \\
\hline Business Digital Adoption Index & $-0.940^{* * *}$ & $-1.113^{* * *}$ & -0.433 & -0.431 \\
& $(-5.66)$ & $(-4.93)$ & $(-1.33)$ & $(-1.32)$ \\
New Firm Density & & & -0.00467 & -0.00428 \\
& & & $(-0.92)$ & $(-0.77)$ \\
Log Real GDP Per Capita PPP & & $-0.123^{* * *}$ & $-0.119^{* * *}$ \\
& & & $(-3.06)$ & $(-2.97)$ \\
Cost of Firm Creation & & & & 0.000441 \\
& & & & $(0.26)$ \\
Constant & $0.910^{* * *}$ & $1.007^{* * *}$ & $1.772^{* * *}$ & $1.723^{* * *}$ \\
& $(9.52)$ & $(7.44)$ & $(7.13)$ & $(6.09)$ \\
\hline Adjusted $R^{2}$ & 0.275 & 0.334 & 0.428 & 0.417 \\
Observations & 83 & 52 & 51 & 51 \\
\hline \hline
\end{tabular}

Sources: World Bank World Development Indicators, Doing Business Report, World Bank Entrepreneurship Report, and World Bank World Development Report 2016. Notes: the self-employment rate is computed as the number of self-employed individuals divided by the labor force in 2016. Digital Adoption Index corresponds to the Business Digital Adoption Index for 2016. New firm density is a proxy of new salaried firm creation that is comparable across economies and is defined as the number of new firm registrations per 1000 individuals. $t$ statistics in parentheses. Standard errors are heteroskedasticity-robust. ${ }^{* * *}$ and ${ }^{* *}$ denote significance levels at the 1 and 5 percent levels, respectively.

Focusing on this subsample, Table 3 shows the following results. First, it confirms that the negative link between self-employment rates and firms' digital adoption documented in 
Section 2 continues to be equally strong and significant in this DEME subsample (column (1) in the table). Second, a similar claim holds when we consider the subsample of DEMEs with available data on new (salaried-)firm density (a proxy for new salaried firm creation) (column (2) in the table) ${ }^{22}$ Third, controlling for new firm density and real GDP per capita, there is no relationship between self-employment rates and firms' digital adoption (column (3) in the table). A similar claim holds if, in addition, we control for the cost of salaried firm creation (column (4) in the table) 23 These empirical results are in line with our model findings where, absent changes in output and new salaried firm creation (and hence firm-creation costs), which takes place when we eliminate the link between $f_{i}$ and $f_{e}$, self-employment remains unchanged. Therefore, Table 3 provides support for the model mechanisms responsible for replicating the stylized facts in Section 2.

Robustness Analysis The Appendix explores alternative parameterizations of the benchmark model. Figures A4, A5, A3, and A2 show that our main findings are robust to alternative elasticities of substitution between self-employment and salaried output, asymmetries in vacancy posting costs between worker categories, and the inclusion of generic (non-ICT) capital in salaried-sector production.

Finally, Figure A8 shows that a version of our model with exogenous labor force participation fails to replicate the empirical relationship between digital adoption and selfemployment rates. This result highlights the relevance of household participation decisions for understanding this relationship.

\section{Conclusion}

We study the link between digital adoption by firms (a precursor to the adoption of automation technologies) and labor market outcomes in developing and emerging economies (DEMEs). Using a large sample of DEMEs, we document a strong, negative, and significant

\footnotetext{
${ }^{22}$ The subsamples in columns (1) and (2) differ because not all DEMEs in our sample have data on new firm density. Hence the smaller number of observations in columns (2) through (4) compared to the number of observations in column (1).

${ }^{23}$ While not shown, replacing the self-employment rate with the unemployment rate in Table 3 confirms that, even in this subsample of DEMEs, there continues to be no significant relationship between the unemployment rate and firms' digital adoption, as in the data.
} 
link between firms' degree of digital adoption and self-employment rates, and the absence of a link between digital adoption and unemployment. These facts hold under a host of other factors associated with differences in self-employment and unemployment across economies, including the level of development and the sectoral composition of employment.

We build a general equilibrium search and matching model with endogenous firm entry and endogenous information-and-communications-technology (ICT)-capital technology adoption, labor force participation, and self-employment that captures key features of DEME labor markets. Under a data-disciplined calibration, our framework generates the empirical relationships between digital adoption, self-employment, and unemployment that we document, both qualitatively and quantitatively. Our analysis suggests that a reduction in the cost of technology adoption alongside a decline in salaried firms' barriers to entry, and not changes in the cost of technology adoption alone, are crucial to quantitatively explain the patterns in the data. These model predictions are corroborated by the data. Our findings stress the role of barriers to salaried-firm creation for a better understanding of the link between firms' technology adoption, the potential for automation, and labor market outcomes in DEMEs. More broadly, our results may be relevant for understanding the evolution of the composition of employment as DEMEs increasingly focus on reforms that facilitate firm creation via the promotion of greater digital adoption and of other technologies by firms and households. 


\section{References}

[1] Acemoglu, Daron, and Pascual Restrepo. 2017. "Robots and Jobs: Evidence from US Labor Markets," NBER Working Paper No. 23285.

[2] Acemoglu, Daron, and Pascual Restrepo. 2018a. "The Race Between Man and Machine: Implications of Technology for Growth, Factor Shares and Employment," American Economic Review, Vol. 108(6), pp. 1488-1542.

[3] Acemoglu, Daron, and Pascual Restrepo. 2018b. "Modeling Automation," mimeo.

[4] Arseneau, David M., and Sanjay K. Chugh. 2012. "Tax Smoothing in Frictional Labor Markets," Journal of Political Economy, Vol. 120, No. 5, pp. 926-985.

[5] Autor, David, and Anna Salomons. 2018. "Is Automation Labor-Displacing? Productivity Growth, Employment, and the Labor Share," NBER Working Paper No. 24871.

[6] Berg, Andrew, Edward F. Buffie, and Luis-Felipe Zanna. 2018. "Should We Fear the Robot Revolution? (The Correct Answer is Yes)," Journal of Monetary Economics, Vol. 97, pp. 117-148.

[7] Bosch, Mariano and William Maloney. 2008. "Cyclical Movements in Unemployment and Informality in Developing Countries," IZA Discussion Paper No. 3514.

[8] Boz, Emine, C. Bora Durdu, and Nan Li. 2015. "Emerging Market Business Cycles: The Role of Labor Market Frictions," Journal of Money, Credit and Banking, Vol. 47(1), pp. $31-72$.

[9] Cairo, Isabel, Shigeru Fujita, and Camilo Morales-Jiménez. 2019. "Elasticities of Labor Supply and Labor Force Participation Flows," Federal Reserve Bank of Philadelphia Working Paper WP 19-03, https://doi.org/10.21799/frbp.wp.2019.03.

[10] Chang, Yongsung, Sun-Bin Kim, Kyooho Kwon, and Richard Rogerson. 2018. "Individual and Aggregate Labor Supply in Heterogeneous Agent Economies with Intensive and Extensive Margins," mimeo.

[11] Chetty, Raj, Adam Guren, Day Manoli, and Andrea Weber. 2011. "Are Micro and Macro Labor Supply Elasticities Consistent? A Review of Evidence on the Intensive and Extensive Margins," American Economic Review Papers and Proceedings, Vol. 101, No. 3, pp. 471-475.

[12] Chetty, Raj, Adam Guren, Day Manoli, and Andrea Weber. 2013. "Does Indivisible Labor Explain the Difference Between Micro and Macro Elasticities? A Meta-Analysis of Extensive Margin Elasticities," NBER Macroeconomics Annual 2012, Vol. 27(1), pp. $1-56$.

[13] Comin, Diego, Mikhail Dmitriev, and Esteban Rossi-Hansberg. 2013. "The Spatial Diusion of Technology," mimeo. 
[14] Comin, Diego, and Bart Hobijn. 2004. "Cross-Country Technology Adoption: Making the Theories Face the Facts," Journal of Monetary Economics, Vol. 51, pp. 39-83.

[15] Comin, Diego, and Bart Hobijn. 2010. "An Exploration of Technol ogy Diffusion," American Economic Review, Vol. 100, pp. 2031-2059.

[16] Comin, Diego, and Marti Mestieri. 2018. "If Technology Has Arrived Everywhere, Why Has Income Diverged?" American Economic Journal: Macroeconomics, Vol. 10, No. 3, pp. 137-178.

[17] Cortes, Guido Matias, Nir Jaimovich, and Henry E. Siu. 2017. "Disappearing Routine Jobs: Who, How, and Why?" Journal of Monetary Economics, Vol. 91, pp. 69-87.

[18] Das, Mitali, and Benjamin Hilgenstock. 2018. "The Exposure to Routinization: Labor Market Implications for Developed and Developing Economies," IMF Working Paper $W P / 18 / 135$.

[19] Den Haan, Wouter J., Garey Ramey, and Joel Watson. 2000. "Job Destruction and the Propagation of Shocks, "char"“" American Economic Review, Vol. 90(3), pp. 482-498.

[20] Eden, Maya, and Paul Gaggl. 2018. "On the Welfare Implications of Automation," Review of Economic Dynamics, Vol. 29, pp. 15-43.

[21] Fiess, Norbert, Marco Fugazza, and William F. Maloney. 2010. "Informal SelfEmployment and Macroeconomic Fluctuations," Journal of Development Economics, Vol. 91, Issue 2, pp. 211-226.

[22] Finkelstein Shapiro, Alan. 2014. "Self-Employment and Business Cycle Persistence: Does the Composition of Employment Matter for Economic Recoveries?," Journal of Economics Dynamics and Control, Vol. Vol. 46, pp. 200-218.

[23] Finkelstein Shapiro, Alan. 2018. "Labor Force Participation, Interest Rate Shocks, and Unemployment Dynamics in Emerging Economies," Journal of Development Economics, Vol. 133, pp. 346-374.

[24] Finkelstein Shapiro, Alan, and Federico S. Mandelman. 2016. "Remittances, Entrepreneurship, and Employment Dynamics over the Business Cycle," Journal of International Economics, Vol. 103, pp. 184-199.

[25] Fiorito, Riccardo, and Giulio Zanella. 2012. "The Anatomy of the Aggregate Labor Supply Elasticity," Review of Economic Dynamics, Vol. 15, pp. 171-187.

[26] Fossen, Frank M., and Alina Sorgner. 2018. "The Effects of Digitalization on Employment and Entrepreneurship," mimeo.

[27] Ghironi, Fabio, and Marc J. Melitz. 2005. "International Trade and Macroeconomic Dynamics with Heterogeneous Firms," Quarterly Journal of Economics, Vol. 120, pp. 865-915. 
[28] Hardy, Wojciech, Piotr Lewandowski, Albert Park, and Du Yang. 2018. "The Global Distribution of Routine and non-regular Work," IBS Working Paper 05/2018.

[29] Jaimovich, Nir, and Henry Siu. 2019. "The Trend is the Cycle: Job Polarization and Jobless Recoveries," Review of Economics and Statistics (forthcoming).

[30] Leduc, Sylvain, and Zheng Liu. 2019. "Robots or Workers? A Macro Analysis of Automation and Labor Markets," Federal Reserve Bank of San Francisco Working Paper 2019-17. https://doi.org/10.24148/wp2019-17.

[31] Maloney, William F., and Carlos Molina. "Are Automation and Trade Polarizing Developing Country Labor Markets, Too?" World Bank Policy Research Working Paper 7922.

[32] Morin, Miguel. 2016. "Computer Adoption and the Changing Labor Market," mimeo.

[33] OECD. 2016a. "Automation and Independent Work in a Digital Economy," Policy Brief on the Future of Work May 2016.

[34] OECD. 2016b. "New Markets and New Jobs," OECD Digital Economy Papers No. 255, 2016 Ministerial Meeting on the Digital Economy Background Report.

[35] OECD. 2016c. "ICTs and Jobs: Complements or Substitutes? The Effects of ICT Investment on Labour Market Demand by Skills and by Industry in Selected OECD Countries," OECD Digital Economy Papers No. 259, 2016 Ministerial Meeting on the Digital Economy Technical Report.

[36] Poschke, Markus. 2019. "Wage Employment, Unemployment and Self-Employment Across Countries," mimeo.

[37] Reijnders, Laurie S.M., and Gaaitzen de Vries. 2018. "Technology, Offshoring and the Rise of non-regular Jobs," Journal of Development Economics, Vol. 135, pp. 412432.

[38] Rogerson, Richard, and Wallenius, Johanna. 2014. "Nonconvexities, Retirement and the Elasticity of Labor Supply," American Economic Review, Vol. 103, pp. 1445-1462.

[39] Rogerson, Richard, and Wallenius, Johanna. 2016. "Retirement, Home Production and Labor Supply Elasticities," Journal of Monetary Economics, Vol. 78, pp. 23-34.

[40] Schlogl, Lukas, and Andy Sumner. 2018. "The Rise of the Robot Reserve Army: Automation and the Future of Economic Development, Work, and Wages in Developing Countries," Center for Global Development Working Paper $48 \%$.

[41] World Bank. 2016. "World Development Report 2016: Digital Dividends," World Bank Group: Washington D.C.

[42] World Bank. 2019. "World Development Report 2019: The Changing Nature of Work," World Bank Group: Washington D.C. 


\section{A Online Appendix}

\section{A.1 Data Details}

\section{A.1.1 List of Countries: Tables 1 and A1}

The baseline list of developing and emerging economies (DEMEs) used in Tables 1 and A1 is comprised of: Afghanistan, Albania, Algeria, Argentina, Armenia, Azerbaijan, Bahamas, Bahrain, Bangladesh, Barbados, Belarus, Belize, Bhutan, Bolivia, Bosnia and Herzegovina, Botswana, Brazil, Brunei, Bulgaria, Burkina Faso, Burundi, Cabo Verde, Cameroon, Chile, China, Colombia, Comoros, Republic of Congo, Costa Rica, Croatia, Dominican Republic, Ecuador, Egypt, El Salvador, Equatorial Guinea, Fiji, Gabon, Georgia, Ghana, Guatemala, Guinea-Bissau, Guyana, Honduras, Hungary, India, Indonesia, Iran, Iraq, Jamaica, Jordan, Kazakhstan, Kenya, Kuwait, Kyrgyz Republic, Lao PDR, Lebanon, Lesotho, Liberia, Macedonia, Madagascar, Malaysia, Maldives, Mali, Mauritania, Mauritius, Mexico, Moldova, Mongolia, Montenegro, Morocco, Mozambique, Namibia, Nepal, Nicaragua, Niger, Nigeria, Oman, Pakistan, Panama, Papua New Guinea, Paraguay, Peru, Philippines, Poland, Qatar, Romania, Russia, Rwanda, Samoa, Saudi Arabia, Senegal, Serbia, Sierra Leone, Solomon Islands, South Africa, Sri Lanka, St. Lucia, Sudan, Syrian Arab Republic, Tajikistan, Tanzania, Thailand, Timor-Leste, Tonga, Trinidad and Tobago, Tunisia, Turkey, Uganda, Ukraine, United Arab Emirates, Uruguay, Uzbekistan, Vanuatu, Venezuela, Vietnam, West Bank and Gaza, Yemen, and Zambia. 


\section{A.2 Robustness Checks: Self-Employment, Unemployment, and Firms' Digital Adoption in 2014}

Table A1: Self-Employment Rates and Business Digital Adoption in DEMEs (2014)

\begin{tabular}{lccccc}
\hline \hline Dep. Var.: Self-Empl. Rate & $(1)$ & $(2)$ & $(3)$ & $(4)$ & $(5)$ \\
\hline Business Digital Adoption Index & $-1.184^{* * *}$ & $-0.554^{* * *}$ & $-0.381^{* * *}$ & $-0.342^{* * *}$ & $-0.387^{* * *}$ \\
& $(-13.01)$ & $(-4.48)$ & $(-3.45)$ & $(-2.90)$ & $(-3.09)$ \\
Log Real GDP Per Capita PPP & & $-0.127^{* * *}$ & $-0.0767^{* * *}$ & $-0.0744^{* * *}$ & $-0.0781^{* * *}$ \\
& & $(-7.98)$ & $(-3.70)$ & $(-3.51)$ & $(-3.72)$ \\
Industrial Empl. Share & & & $-0.581^{* * *}$ & $-0.622^{* * *}$ & $-0.624^{* * *}$ \\
& & & $(-3.55)$ & $(-3.70)$ & $(-3.75)$ \\
Services Empl. Share & & $-0.315^{* * *}$ & $-0.354^{* * *}$ & $-0.357^{* * *}$ \\
& & $(-2.71)$ & $(-3.10)$ & $(-3.08)$ \\
Min. Wage/VA per Worker & & & & $0.0006^{* * *}$ & $0.0006^{* * *}$ \\
& & & & $(2.77)$ & $(2.78)$ \\
Severance Payment & & & & $(1.15)$ & $(1.07)$ \\
& & & & & 0.0212 \\
Government Effectiveness & & & & $(0.87)$ \\
Constant & $0.997^{* * *}$ & $1.835^{* * *}$ & $1.568^{* * *}$ & $1.543^{* * *}$ & $1.607^{* * *}$ \\
& $(19.81)$ & $(18.02)$ & $(12.39)$ & $(11.69)$ & $(10.99)$ \\
\hline Adjusted $R^{2}$ & 0.589 & 0.717 & 0.765 & 0.778 & 0.778 \\
Observations & 119 & 116 & 116 & 112 & 112 \\
\hline \hline
\end{tabular}

Sources: World Bank World Development Indicators, Doing Business Report, and World Bank World Development Report 2016 (http://www.worldbank.org/en/publication/wdr2016/Digital-Adoption-Index). Notes: the self-employment rate is computed as the number of self-employed individuals divided by the labor force in 2014. Digital Adoption Index corresponds to the Business Digital Adoption Index in 2014. The severance payment represents pay for redundancy dismissal for a worker with 5 years of tenure (expressed in salary weeks). See Appendix A.1.1 for the list of economies used in this table. $t$ statistics in parentheses. Standard errors are heteroskedasticity-robust. ${ }^{* * *}$ and ${ }^{* *}$ denote significance at the 1 and 5 percent levels, respectively. 
Table A2: Unemployment Rates and Business Digital Adoption in DEMEs (2014)

\begin{tabular}{lccccc}
\hline \hline Dep. Var.: Unempl. Rate & $(1)$ & $(2)$ & $(3)$ & $(4)$ & $(5)$ \\
\hline Business Digital Adoption Index & 0.0558 & $0.0947^{*}$ & 0.0407 & 0.0216 & 0.0160 \\
& $(1.51)$ & $(1.78)$ & $(0.67)$ & $(0.34)$ & $(0.22)$ \\
Log Real GDP Per Capita PPP & & -0.00594 & $-0.0179^{*}$ & -0.0181 & -0.0185 \\
& & $(-0.71)$ & $(-1.71)$ & $(-1.62)$ & $(-1.60)$ \\
Industrial Empl. Share & & & 0.0886 & 0.107 & 0.107 \\
& & & $(0.96)$ & $(1.16)$ & $(1.15)$ \\
Services Empl. Share & & & $0.109^{* *}$ & $0.115^{* *}$ & $0.115^{* *}$ \\
& & & & -0.000129 & -0.000129 \\
Min. Wage/VA per Worker & & & & $(-1.50)$ & $(-1.48)$ \\
& & & & -0.000524 & -0.000529 \\
Severance Payment & & & & $(-1.55)$ & $(-1.55)$ \\
& & & & & 0.00265 \\
Government Effectiveness & & & & $(2.17)$ \\
& & & & & \\
Constant & $0.0534^{* * *}$ & 0.0861 & $0.149^{* *}$ & $0.162^{* *}$ & $0.170^{* *}$ \\
& $(2.89)$ & $(1.42)$ & $(2.16)$ & $(2.27)$ & $(2.01)$ \\
\hline Adjusted $R^{2}$ & 0.009 & 0.013 & 0.043 & 0.050 & 0.041 \\
Observations & 119 & 116 & 116 & 112 & 112 \\
\hline \hline
\end{tabular}

Sources: World Bank World Development Indicators, Doing Business Report, and World Bank World Development Report 2016 (http://www.worldbank.org/en/publication/wdr2016/Digital-Adoption-Index). Notes: the self-employment rate is computed as the number of self-employed individuals divided by the labor force in 2014. Digital Adoption Index corresponds to the Business Digital Adoption Index in 2014. The severance payment represents pay for redundancy dismissal for a worker with 5 years of tenure (expressed in salary weeks). See Appendix A.1.1 for the list of economies used in this table. $t$ statistics in parentheses. Standard errors are heteroskedasticity-robust. ${ }^{* * *},{ }^{* *}$, and ${ }^{*}$ denote significance at the 1,5 , and 10 percent levels, respectively. 
Table A3: Self-Employment Rates and Business Digital Adoption in Advanced Economies (AEs) (2016)

\begin{tabular}{lccccc}
\hline \hline & $(1)$ & $(2)$ & $(3)$ & $(4)$ & $(5)$ \\
\hline Business Digital Adoption Index & $-0.238^{* *}$ & -0.185 & -0.133 & -0.0842 & -0.0869 \\
& $(-2.07)$ & $(-1.63)$ & $(-1.55)$ & $(-0.91)$ & $(-0.89)$ \\
Log Real GDP Per Capita PPP & & -0.0215 & -0.00865 & -0.0000951 & 0.00284 \\
& & $(-0.99)$ & $(-0.32)$ & $(-0.00)$ & $(0.10)$ \\
Industrial Empl. Share & & $-0.675^{*}$ & -0.632 & -0.593 \\
& & $(-1.84)$ & $(-1.68)$ & $(-1.63)$ \\
Services Empl. Share & & $-0.577^{*}$ & -0.541 & -0.494 \\
& & & $(-1.78)$ & $(-1.62)$ & $(-1.44)$ \\
Min. Wage/VA per Worker & & & 0.0241 & 0.0187 \\
& & & & $(0.54)$ & $(0.38)$ \\
Severance Payment & & & & $(1.43)$ & $(1.03)$ \\
& & & & & -0.00924 \\
Government Effectiveness & & & & & $(-0.33)$ \\
Constant & & & & & \\
& & & & & \\
& & & & & \\
Adjusted $R^{2}$ & $(3.32)$ & $(2.21)$ & $(2.47)$ & $(1.88)$ & $(1.76)$ \\
Observations & 0.166 & 0.163 & 0.259 & 0.248 & 0.218 \\
\hline \hline
\end{tabular}

Sources: World Bank World Development Indicators, Doing Business Report, and World Bank World Development Report 2016 (http://www.worldbank.org/en/publication/wdr2016/Digital-Adoption-Index). Notes: the self-employment rate is computed as the number of self-employed individuals divided by the labor force in 2016. Digital Adoption Index corresponds to the Business Digital Adoption Index in 2016. The severance payment represents pay for redundancy dismissal for a worker with 5 years of tenure (expressed in salary weeks). The list of AEs is comprised of: Australia, Austria, Belgium, Canada, Czech Republic, Denmark, Estonia, Finland, France, Germany, Hong Kong, Iceland, Ireland, Israel, Japan, Latvia, Lithuania, Luxembourg, Netherlands, New Zealand, Norway, Portugal, Singapore, Slovak Republic, Slovenia, Spain, Sweden, Switzerland, United Kingdom, and United States. $t$ statistics in parentheses. Standard errors are heteroskedasticity-robust. ${ }^{* *},{ }^{* *}$, and ${ }^{*}$ denote significance at the 1,5 , and 10 percent levels, respectively.

\section{A.3 Equilibrium Conditions: Benchmark Model}

Taking aggregate productivity $z_{t}$ as given, the allocations and prices $\left\{c_{t}, Y_{e, t}, \widetilde{y}_{r, t}, \widetilde{y}_{i, t}, Y_{t}, p_{s, t}\right\}$, $\left\{p_{e, t}, N_{t}, N_{i, t}, \widetilde{d}_{r, t}, \widetilde{d}_{i, t}, \widetilde{d}_{t}, m c_{r, t}, m c_{i, t}, \widetilde{a}_{i, t}, \widetilde{\rho}_{r, t}, \widetilde{\rho}_{i, t}, Y_{s, t}, \widetilde{a}_{s}, a_{i, t}, n_{r, t}^{r}, n_{r, t}^{i}, n_{i, t}^{i}, \omega_{t}, r_{i, t}, v_{i, t}, v_{r, t}, k_{i, t}\right\}$ and $\left\{n_{r, t}, n_{e, t}, N_{e, t}, w_{r, t}^{r}, w_{r, t}^{i}, w_{i, t}^{i}, s_{r, t}, s_{i, t}, s_{e, t}\right\}$ satisfy: 


$$
\begin{aligned}
& Y_{t}=c_{t}+\left(k_{i, t+1}-\left(1-\delta_{i}\right) k_{i, t}\right)+\psi_{r} v_{r, t}+\psi_{i} v_{i, t}+f_{e} N_{e, t}+f_{i} N_{i, t}, \\
& Y_{e, t}=z_{t} n_{e, t} \\
& z_{t} G\left(n_{r, t}^{r}\right)=N_{t}\left(\frac{\widetilde{y}_{r, t}}{\widetilde{a}_{s}}\right) \\
& z_{t} F\left(n_{i, t}^{i}, n_{r, t}^{i}, k_{i, t}\right)=N_{i, t}\left(\frac{\widetilde{y}_{i, t}}{\widetilde{a}_{i, t}}\right) \\
& Y_{t}=\left[Y_{s, t}^{\frac{\phi_{y}-1}{\phi_{y}}}+Y_{e, t}^{\frac{\phi_{y}-1}{\phi_{y}}}\right]^{\frac{\phi_{y}}{\phi_{y}-1}} \\
& Y_{s, t}=\left(p_{s, t}\right)^{-\phi_{y}} Y_{t} \\
& Y_{e, t}=\left(p_{e, t}\right)^{-\phi_{y}} Y_{t} \\
& N_{t}=(1-\delta)\left[N_{t-1}+N_{e, t-1}\right] \\
& N_{i, t}=\left(\frac{a_{m i n}}{\widetilde{a}_{i, t}}\right)^{-k_{p}}\left(\frac{k_{p}}{k_{p}-(\varepsilon-1)}\right)^{\frac{k_{p}}{\varepsilon-1}} N_{t} \text {, } \\
& \widetilde{d}_{r, t}=\left[\widetilde{\rho}_{r, t}-\frac{m c_{r, t}}{\widetilde{a}_{s}}\right] \widetilde{y}_{r, t} \\
& \widetilde{d}_{i, t}=\left[\widetilde{\rho}_{i, t}-\frac{m c_{i, t}}{\widetilde{a}_{i, t}}\right] \widetilde{y}_{i, t}-f_{i} \\
& \widetilde{d}_{t}=\widetilde{d}_{r, t}+\frac{N_{i, t}}{N_{t}} \widetilde{d}_{i, t}, \\
& \widetilde{\rho}_{r, t}=\frac{\varepsilon}{\varepsilon-1} \frac{m c_{r, t}}{\widetilde{a}_{s}}, \\
& \widetilde{\rho}_{i, t}=\frac{\varepsilon}{\varepsilon-1} \frac{m c_{i, t}}{\widetilde{a}_{i, t}}, \\
& \widetilde{d}_{i, t}=\left[\frac{\varepsilon-1}{k_{p}-(\varepsilon-1)}\right] f_{i}, \\
& \widetilde{y}_{r, t}=\left(\widetilde{\rho}_{r, t} / p_{s, t}\right)^{-\varepsilon} Y_{s, t} \text {, } \\
& \widetilde{y}_{i, t}=\left(\widetilde{\rho}_{i, t} / p_{s, t}\right)^{-\varepsilon} Y_{s, t}, \\
& p_{s, t}=\left[N_{t}\left(\widetilde{\rho}_{r, t}\right)^{1-\varepsilon}+N_{i, t}\left(\widetilde{\rho}_{i, t}\right)^{1-\varepsilon}\right]^{\frac{1}{1-\varepsilon}},
\end{aligned}
$$




$$
\begin{aligned}
& \widetilde{a}_{s}=\left(\frac{k_{p}}{k_{p}-(\varepsilon-1)}\right)^{\frac{1}{\varepsilon-1}} a_{\min } \\
& \widetilde{a}_{i, t}=\left(\frac{k_{p}}{k_{p}-(\varepsilon-1)}\right)^{\frac{1}{\varepsilon-1}} a_{i, t} \\
& n_{r, t+1}=\left(1-\rho_{s}\right)\left[n_{r, t}+v_{r, t} q\left(\theta_{r, t}\right)\right] \text {, } \\
& n_{i, t+1}^{i}=\left(1-\rho_{s}\right)\left[n_{i, t}^{i}+v_{i, t}^{i} q\left(\theta_{i, t}\right)\right], \\
& r_{i, t}=m c_{i, t} z_{t} F_{k_{i}, t}, \\
& \frac{\psi_{r}}{q\left(\theta_{r, t}\right)}=\left(1-\rho_{s}\right) \mathbb{E}_{t} \Xi_{t+1 \mid t}\left[\begin{array}{c}
\left(1-\omega_{t+1}\right)\left[m c_{r, t+1} z_{t+1} G_{n_{r}^{r}, t+1}-w_{r, t+1}^{r}\right] \\
+\omega_{t+1}\left[m c_{i, t+1} z_{t+1} F_{n_{r}^{i}, t+1}-w_{r, t+1}^{i}\right]+\frac{\psi_{r}}{q\left(\theta_{r, t+1}\right)}
\end{array}\right], \\
& \frac{\psi_{i}}{q\left(\theta_{i, t}\right)}=\left(1-\rho_{s}\right) \mathbb{E}_{t} \Xi_{t+1 \mid t}\left[m c_{i, t+1} z_{t+1} F_{n_{i}^{i}, t+1}-w_{i, t+1}^{i}+\frac{\psi_{i}}{q\left(\theta_{i, t+1}\right)}\right] \text {, } \\
& m c_{i, t} z_{t} F_{n_{r}^{i}, t}-w_{r, t}^{i}=m c_{r, t} z_{t} G_{n_{r}^{r}, t}-w_{r, t}^{r}, \\
& 1=\mathbb{E}_{t} \Xi_{t+1 \mid t}\left[r_{i, t+1}+\left(1-\delta_{i}\right)\right], \\
& n_{e, t+1}=\left(1-\rho_{e}\right)\left[n_{e, t}+s_{e, t} \phi_{e}\right] \\
& f_{e}=(1-\delta) \mathbb{E}_{t} \Xi_{t+1 \mid t}\left[\widetilde{d}_{t+1}+f_{e}\right], \\
& n_{r, t}^{r}=\left(1-\omega_{t}\right) n_{r, t}, \\
& n_{r, t}^{i}=\omega_{t} n_{r, t}, \\
& \mathbf{W}_{r, t}^{r}=\left(\frac{\nu}{1-\nu}\right) \mathbf{J}_{r, t}^{r}, \\
& \mathbf{W}_{r, t}^{i}=\left(\frac{\nu}{1-\nu}\right) \mathbf{J}_{r, t}^{i}, \\
& \mathbf{W}_{i, t}^{i}=\left(\frac{\nu}{1-\nu}\right) \mathbf{J}_{i, t}^{i},
\end{aligned}
$$

$$
\begin{aligned}
& \frac{\mathbf{h}_{l f p_{r, t}}}{\mathbf{u}^{\prime}\left(c_{t}\right)} \frac{1}{f\left(\theta_{r, t}\right)}=\left(1-\rho_{s}\right) \mathbb{E}_{t} \Xi_{t+1 \mid t}\left[w_{r, t+1}^{r}\left(1-\omega_{t+1}\right)+w_{r, t+1}^{i} \omega_{t+1}+\left(\frac{1}{f\left(\theta_{r, t+1}\right)}-1\right) \frac{\mathbf{h}_{l f p_{r, t+1}}}{\mathbf{u}^{\prime}\left(c_{t+1}\right)}\right], \\
& \frac{\mathbf{h}_{l f p_{i, t}}}{\mathbf{u}^{\prime}\left(c_{t}\right)} \frac{1}{f\left(\theta_{i, t}\right)}=\left(1-\rho_{s}\right) \mathbb{E}_{t} \Xi_{t+1 \mid t}\left[w_{i, t+1}^{i}+\left(\frac{1}{f\left(\theta_{i, t+1}\right)}-1\right) \frac{\mathbf{h}_{l f p_{i, t+1}}}{\mathbf{u}^{\prime}\left(c_{t+1}\right)}\right],
\end{aligned}
$$




$$
\frac{\mathbf{h}_{l f p_{e, t}}}{\mathbf{u}^{\prime}\left(c_{t}\right)} \frac{1}{\phi_{e}}=\left(1-\rho_{e}\right) \mathbb{E}_{t} \Xi_{t+1 \mid t}\left[p_{e, t+1} z_{t+1}+\left(\frac{1}{\phi_{e}}-1\right) \frac{\mathbf{h}_{l f p_{e, t+1}}}{\mathbf{u}^{\prime}\left(c_{t+1}\right)}\right],
$$

where the following value functions are used in the implicit expressions for the wages:

$$
\begin{aligned}
& \mathbf{W}_{r, t}^{r}=w_{r, t}^{r}-\frac{\mathbf{h}^{\prime}\left(l f p_{r, t}\right)}{\mathbf{u}^{\prime}\left(c_{t}\right)}+\left(1-\rho_{s}\right) \mathbb{E}_{t} \Xi_{t+1 \mid t} \mathbf{W}_{r, t+1}^{r}, \\
& \mathbf{W}_{r, t}^{i}=w_{r, t}^{i}-\frac{\mathbf{h}^{\prime}\left(l f p_{r, t}\right)}{\mathbf{u}^{\prime}\left(c_{t}\right)}+\left(1-\rho_{s}\right) \mathbb{E}_{t} \Xi_{t+1 \mid t} \mathbf{W}_{r, t+1}^{i}, \\
& \mathbf{W}_{i, t}^{i}=w_{i, t}^{i}-\frac{\mathbf{h}^{\prime}\left(l f p_{i, t}\right)}{\mathbf{u}^{\prime}\left(c_{t}\right)}+\left(1-\rho_{s}\right) \mathbb{E}_{t} \Xi_{t+1 \mid t} \mathbf{W}_{i, t+1}^{i}, \\
& \mathbf{J}_{r, t}^{r}=m c_{r, t} z_{t} G_{n_{r, t}^{r}}-w_{r, t}^{r}+\left(1-\rho_{s}\right) \mathbb{E}_{t} \Xi_{t+1 \mid t} \mathbf{J}_{r, t+1}^{r}, \\
& \mathbf{J}_{r, t}^{i}=m c_{i, t} z_{t} F_{n_{r, t}^{i}}-w_{r, t}^{i}+\left(1-\rho_{s}\right) \mathbb{E}_{t} \Xi_{t+1 \mid t} \mathbf{J}_{r, t+1}^{i}, \\
& \mathbf{J}_{i, t}^{i}=m c_{i, t} z_{t} F_{n_{i, t}^{i}}-w_{i, t}^{i}+\left(1-\rho_{s}\right) \mathbb{E}_{t} \Xi_{t+1 \mid t} \mathbf{J}_{i, t+1}^{i} .
\end{aligned}
$$

\section{A.4 Robustness Analysis: Details}

\section{Alternative Elasticities of Substitution Between Salaried and Self-Employment}

Output Figures A4 and A5 present analogous figures to Figure A1 for lower and higher values for the elasticity of substitution between salaried and self-employment output $\left(\phi_{y}\right)$. Inspection of the two figures shows that, the greater the elasticity is, the closer the model gets to matching the change in the cost of creating a salaried firm (as a share of income), and the closer it gets to quantitatively matching the reduction in self-employment rates as digital adoption increases. More broadly, our conclusions regarding the link between digital adoption, self-employment, and unemployment remain unchanged.

Asymmetry in Vacancy Costing Costs of $i$ and $r$ Salaried Workers Our baseline framework assumes identical vacancy posting costs for $i$ and $r$ salaried workers. Figure A3 shows that assuming that posting $i$ vacancies is more expensive than posting $r$ vacancies does not change any of our findings (for illustrative purposes, we assume that $i$ vacancies are twice as expensive as $r$ vacancies). 
Model with Exogenous Labor Force Participation Standard search and matching models generally assume exogenous labor force participation. In contrast, our framework incorporates endogenous participation. This model feature plays an important role by allowing households to reallocate their household members across employment categories in response to changes in the sunk-entry and fixed technology-adoption costs of salaried firms. Figure A8 shows that a version of our model with exogenous labor force participation fails to replicate the empirical relationship between digital adoption and self-employment rates, thereby stressing the relevance of household participation decisions for understanding this relationship.

Generic Capital in Production of Salaried Intermediate Goods Our baseline framework assumes that $r$ firms only use salaried labor to produce and $i$ firms use salaried labor and ICT capital to produce. For completeness, the next section below presents the details of a richer version of our baseline model where intermediate-goods firms also use generic capital to produce $r$ and $i$ intermediate goods. Figure A2 below shows that our baseline findings remain unchanged in this richer production environment with generic capital usage among salaried firms. In fact, with generic capital included as an additional input in the production process of salaried intermediate goods, the model is able to generate a relationship between digital adoption and self-employment rates that is quantitatively closer to the data compared to the link generated by our simpler, baseline model in the main text. Importantly, though, these findings suggest that the main mechanisms of our baseline model remain unchanged once we incorporate a richer production structure and confirm that nothing is lost by using a simpler economic environment.

\section{A.5 Benchmark Model with Generic Capital in Salaried Produc- tion: Relevant Details}

In what follows, we present the relevant sections of the benchmark model that are modified to incorporate generic capital into the salaried intermediate-goods production process. Unless

otherwise noted, the model sections that are not discussed below remain unchanged relative to the model in the main text. 


\section{A.6 Salaried Intermediate-Goods Firms}

There is a measure one of perfectly-competitive salaried firms that produce intermediate goods for salaried wholesale firms. In particular, intermediate-goods firms produce two different categories of intermediate goods, $r$ and $i$, using two different production technologies. The first technology produces $r$ intermediate goods using $r$ salaried workers $n_{r, t}^{r}$ and generic physical capital $k_{g, t}^{r}$, where salaried employment and generic capital are combined using a Cobb-Douglas technology. The second technology produces $i$ intermediate goods using generic physical capital $k_{g, t}^{i}, i$ salaried workers $n_{i, t}^{i}$, ICT capital $k_{i, t}$, and $r$ salaried workers $n_{r, t}^{i}$, ICT capital and $i$ labor are used as complements. $r$ salaried labor is imperfectly substitutable with the ICT-capital-i-labor composite. In turn, the ICT-capital-i-labor composite and $r$ salaried labor make up an ICT capital-salaried (both $i$ and $r$ )-labor composite, which is a complement in production with generic physical capital. As in the baseline model in the main text, total $r$ salaried employment is $n_{r, t} \equiv n_{r, t}^{r}+n_{r, t}^{i}$.

As in the benchmark model, firms spend resources to post vacancies $v_{i, t}$ and $v_{r, t}$ to hire new $i$ and $r$ salaried workers, respectively. Once firms hire $r$ workers, they choose how to allocate them between the two production technologies by choosing the share $\omega_{t}$ of total $r$ salaried employment $n_{r, t}$ allocated to the production of $i$ intermediate goods. Then, it follows that $n_{r, t}^{r}=\left(1-\omega_{t}\right) n_{r, t}$ and $n_{r, t}^{i}=\omega_{t} n_{r, t}$. We use these definitions further below. In contrast, $i$ workers are only used in the production of $i$ intermediate goods. Given our assumptions about the relationship between inputs $n_{i, t}^{i}, n_{r, t}^{i}, k_{g, t}^{i}$, and $k_{i, t}$ in the production of $i$ intermediate goods, one way to think about $i$ and $r$ workers is as non-routine and routine salaried workers, respectively, and the $r$ and $i$ production technologies as the routine and non-routine production technologies, respectively.

Formally, intermediate-goods firms choose vacancies $v_{r, t}$ and $v_{i, t}$, the desired measure of $r$

and $i$ workers $n_{r, t+1}$ and $n_{i, t+1}^{i}$, the fraction $\omega_{t}$ of total $r$ salaried labor $n_{r, t}$ that is allocated to the production of $i$ intermediate goods, and accumulate both ICT capital $k_{i, t+1}$ and generic 
capital $k_{g, t+1}^{r}$ and $k_{g, t+1}^{i}$ to maximize $\mathbb{E}_{0} \sum_{t=0}^{\infty} \Xi_{t \mid 0} \Pi_{s, t}$ subject to

$$
\begin{gathered}
\Pi_{s, t}=\left[m c_{r, t} z_{t} G\left(n_{r, t}^{r}, k_{g, t}^{r}\right)-w_{r, t}^{r} n_{r, t}^{r}-\left(k_{g, t+1}^{r}-\left(1-\delta_{g}\right) k_{g, t}^{r}\right)-\psi_{r} v_{r, t}\right] \\
+\left[m c_{i, t} z_{t} F\left(n_{r, t}^{i}, n_{i, t}^{i}, k_{i, t}, k_{g, t}^{i}\right)-w_{i, t}^{i} n_{i, t}^{i}-w_{r, t}^{i} n_{r, t}^{i}\right. \\
-\left(k_{i, t+1}-\left(1-\delta_{i}\right) k_{i, t}\right)-\left(k_{g, t+1}^{i}-\left(1-\delta_{g}\right) k_{g, t}^{i}\right)-\psi_{i} v_{i, t} \\
n_{r, t+1}=\left(1-\rho_{s}\right)\left[n_{r, t}+v_{r, t} q\left(\theta_{r, t}\right)\right] \\
n_{i, t+1}^{i}=\left(1-\rho_{s}\right)\left[n_{i, t}^{i}+v_{i, t} q\left(\theta_{i, t}\right)\right]
\end{gathered}
$$

and the fact that

$$
n_{r, t}^{r}=\left(1-\omega_{t}\right) n_{r, t}
$$

and

$$
n_{r, t}^{i}=\omega_{t} n_{r, t}
$$

where the production functions $G\left(n_{r, t}^{r}, k_{g, t}^{r}\right)$ and $F\left(n_{i, t}^{i}, n_{r, t}^{i}, k_{i, t}, k_{g, t}^{i}\right)$ are constant-returns-toscale and $z_{t}$ is aggregate productivity. $\psi_{r}$ and $\psi_{i}$ are the flow costs of posting a vacancy for workers who produce $r$ and $i$ intermediate goods, respectively; $w_{r, t}^{r}$ and $w_{r, t}^{i}$ are the real wages of $r$ workers producing $r$ and $i$ intermediate goods, respectively; $w_{i, t}^{i}$ is the real wage of $i$ workers; and $q\left(\theta_{r, t}\right)$ and $q\left(\theta_{i, t}\right)$ are the corresponding job-filling probabilities (which are a function of market tightness $\theta_{r, t}$ and $\theta_{i, t}$ ), all of which are taken as given by firms. $\delta_{i}$ is the depreciation rate of ICT capital, $\delta_{r}$ is the depreciation rate of generic capital, and $\rho_{s}$ is the exogenous separation probability of salaried workers.

The first-order conditions yield standard ICT capital and generic capital Euler equations

$$
\begin{aligned}
& 1=\mathbb{E}_{t} \Xi_{t+1 \mid t}\left[r_{i, t+1}+\left(1-\delta_{i}\right)\right], \\
& 1=\mathbb{E}_{t} \Xi_{t+1 \mid t}\left[r_{g, t+1}^{i}+\left(1-\delta_{g}\right)\right],
\end{aligned}
$$

and

$$
1=\mathbb{E}_{t} \Xi_{t+1 \mid t}\left[r_{g, t+1}^{r}+\left(1-\delta_{g}\right)\right]
$$

where $r_{i, t} \equiv m c_{i, t} z_{t} F_{k_{i}, t}, r_{g, t}^{i} \equiv m c_{i, t} z_{t} F_{k_{g}^{i}, t}$, and $r_{g, t}^{r} \equiv m c_{r, t} z_{t} G_{k_{g}^{r}, t}$; an optimal decision over 
the allocation of $r$ workers across the production of $r$ and $i$ intermediate goods, $\omega_{t}$, that yields 24

$$
m c_{i, t} z_{t} F_{n_{r}^{i}, t}-w_{r, t}^{i}=m c_{r, t} z_{t} G_{n_{r}^{r}, t}-w_{r, t}^{r}
$$

as well as standard job creation conditions for salaried employment used in each of the intermediate-goods categories

$$
\frac{\psi_{r}}{q\left(\theta_{r, t}\right)}=\left(1-\rho_{s}\right) \mathbb{E}_{t} \Xi_{t+1 \mid t}\left[\begin{array}{c}
\left(1-\omega_{t+1}\right)\left[m c_{r, t+1} z_{t+1} G_{n_{r}^{r}, t+1}-w_{r, t+1}^{r}\right] \\
+\omega_{t+1}\left[m c_{i, t+1} z_{t+1} F_{n_{r}^{i}, t+1}-w_{r, t+1}^{i}\right]+\frac{\psi_{r}}{q\left(\theta_{r, t+1}\right)}
\end{array}\right]
$$

and

$$
\frac{\psi_{i}}{q\left(\theta_{i, t}\right)}=\left(1-\rho_{s}\right) \mathbb{E}_{t} \Xi_{t+1 \mid t}\left[m c_{i, t+1} z_{t+1} F_{n_{i} w_{i, t}, t+1}-w_{i, t+1} w_{i, t}+\frac{\psi_{i}}{q\left(\theta_{i, t+1}\right)}\right] .
$$

The optimal allocation of $r$ workers across the two production technologies is intuitive: firms equate the net marginal revenue product of labor from allocating an $r$ worker to the production of $r$ intermediate goods to the corresponding net marginal revenue product of labor from allocating the worker to the production of $i$ intermediate goods. The capital Euler and job creation conditions are standard. Each job creation condition equates the expected marginal cost of posting a vacancy to the expected marginal benefit, where the latter is given by the marginal product of labor net of the real wage and the continuation value of the employment relationship. In the case of the job creation condition for $r$ workers, the expected marginal benefit of posting a vacancy is given by the weighted average of the revenue marginal product of labor net of the wage for the two categories of $r$ workers, where the weights are optimally chosen when firms allocate $r$ workers across the two production technologies.

\footnotetext{
${ }^{24}$ To obtain the following condition, we note that both $n_{r, t}^{r}=\left(1-\omega_{t}\right) n_{r, t}$ and $n_{r, t}^{i}=\omega_{t} n_{r, t}$ are expressions that intermediate-goods firms explicitly take into account when optimally choosing how to allocate $r$ workers across the two production technologies.
} 


\section{A.7 Symmetric Equilibrium and Market Clearing}

Output produced by salaried intermediate-goods firms with the $r$ production technology must be equal to total output by salaried wholesale firms who use $r$ intermediate goods:

$$
z_{t} G\left(n_{r, t}^{r}, k_{g, t}^{r}\right)=N_{t}\left(\frac{\widetilde{y}_{r, t}}{\widetilde{a}_{s}}\right)
$$

Analogously, output produced by salaried intermediate-goods firms with the $i$ production technology must be equal to total output by salaried wholesale firms who use $i$ intermediate goods:

$$
z_{t} F\left(n_{i, t}^{i}, n_{r, t}^{i}, k_{i, t}, k_{g, t}^{i}\right)=N_{i, t}\left(\frac{\widetilde{y}_{i, t}}{\widetilde{a}_{i, t}}\right) .
$$

Finally, the resource constraint of the economy is given by

$$
Y_{t}=c_{t}+i n v_{i, t}+i n v_{g, t}+\psi_{r} v_{r, t}+\psi_{i} v_{i, t}+f_{e} N_{e, t}+f_{i} N_{i, t}
$$

where $i n v_{i, t}=k_{i, t+1}-\left(1-\delta_{i}\right) k_{i, t}$ and $i n v_{g, t}=k_{g, t+1}^{r}+k_{g, t+1}^{i}-\left(1-\delta_{g}\right)\left(k_{g, t}^{r}+k_{g, t}^{i}\right)$.

For the quantitative analysis, we assume that salaried production of $r$ intermediate goods is Cobb-Douglas between salaried labor and generic capital with capital share $0<\alpha_{r}<1$. In turn, salaried production of $i$ intermediate goods is given by a similar Cobb Douglasaggregator, but in this case it is an aggregator of the production function for $i$ intermediate goods in the main text and generic capital $k_{g, t}^{i}$, with a generic capital share $0<\alpha_{i}<1$. We adopt the same parameter values and calibration targets used for the baseline model, and set $\delta_{i}=\delta_{g}$ and $\alpha_{i}=\alpha_{r}=0.32$, consistent with the macro literature. 
Figure A1: Digital Adoption by Firms and New Firm Density: Data vs. Model

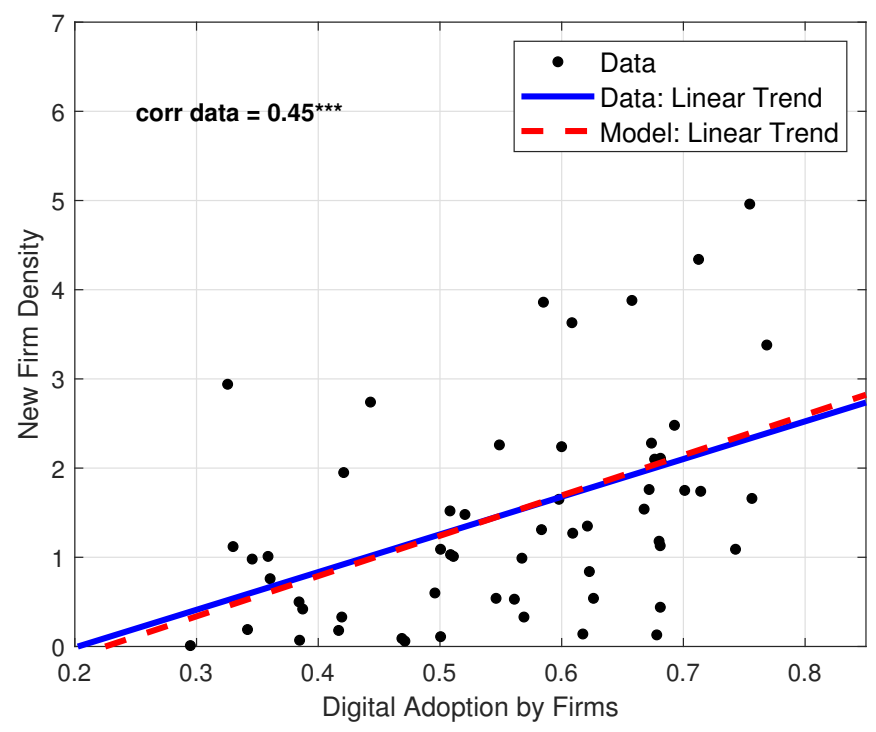

Sources: World Bank World Development Report 2016 and World Bank Entrepreneurship Report. Notes: New firm density, a proxy for new salaried firm creation that is comparable across countries, is defined as the number of new firm registrations per 1000 individuals ages 15-64. 
Figure A2: ICT-Capital Technology Adoption and Labor Market Outcomes: Data vs. Baseline Model with Generic Capital and ICT Capital
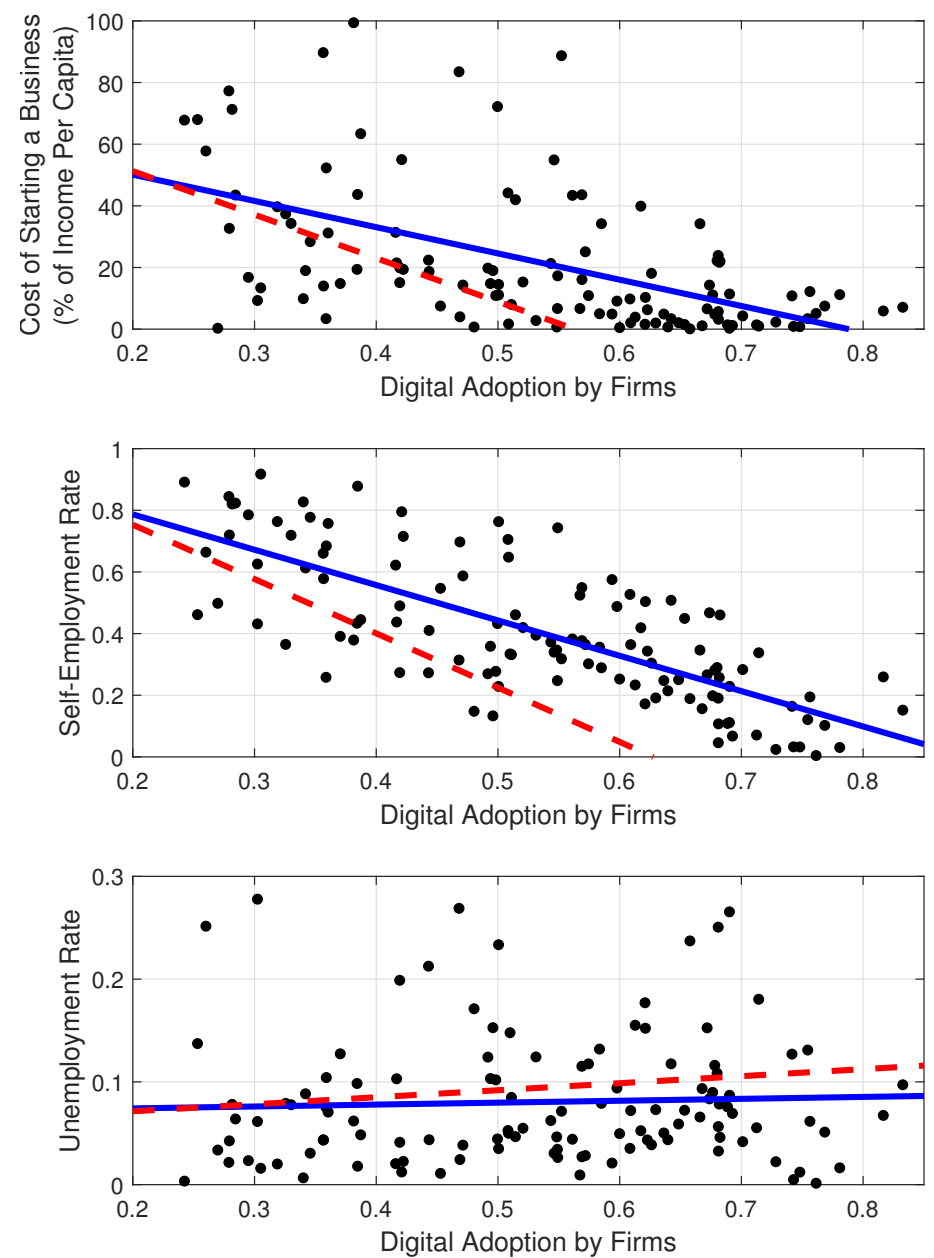

- Data - Data: Linear Trend - - Model: Linear Trend 
Figure A3: ICT-Capital Technology Adoption and Labor Market Outcomes: Data vs. Baseline Model with Asymmetric Vacancy Posting Costs for $i$ and $r$ Salaried Employment
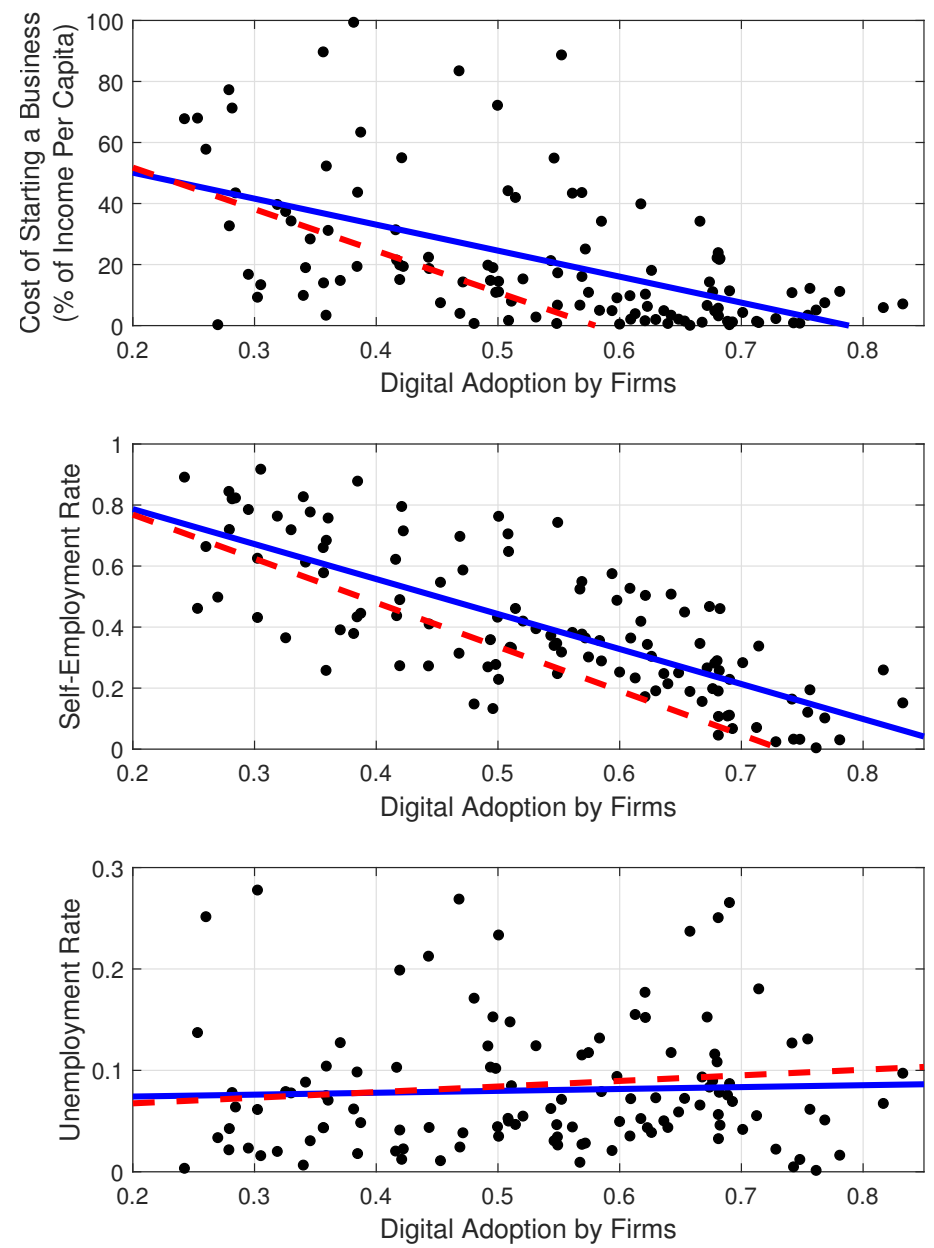

- Data $\longrightarrow$ Data: Linear Trend - - Model: Linear Trend 
Figure A4: ICT-Capital Technology Adoption and Labor Market Outcomes: Data vs. Baseline Model with Lower Elasticity of Substitution between Salaried and Self-Employment Output
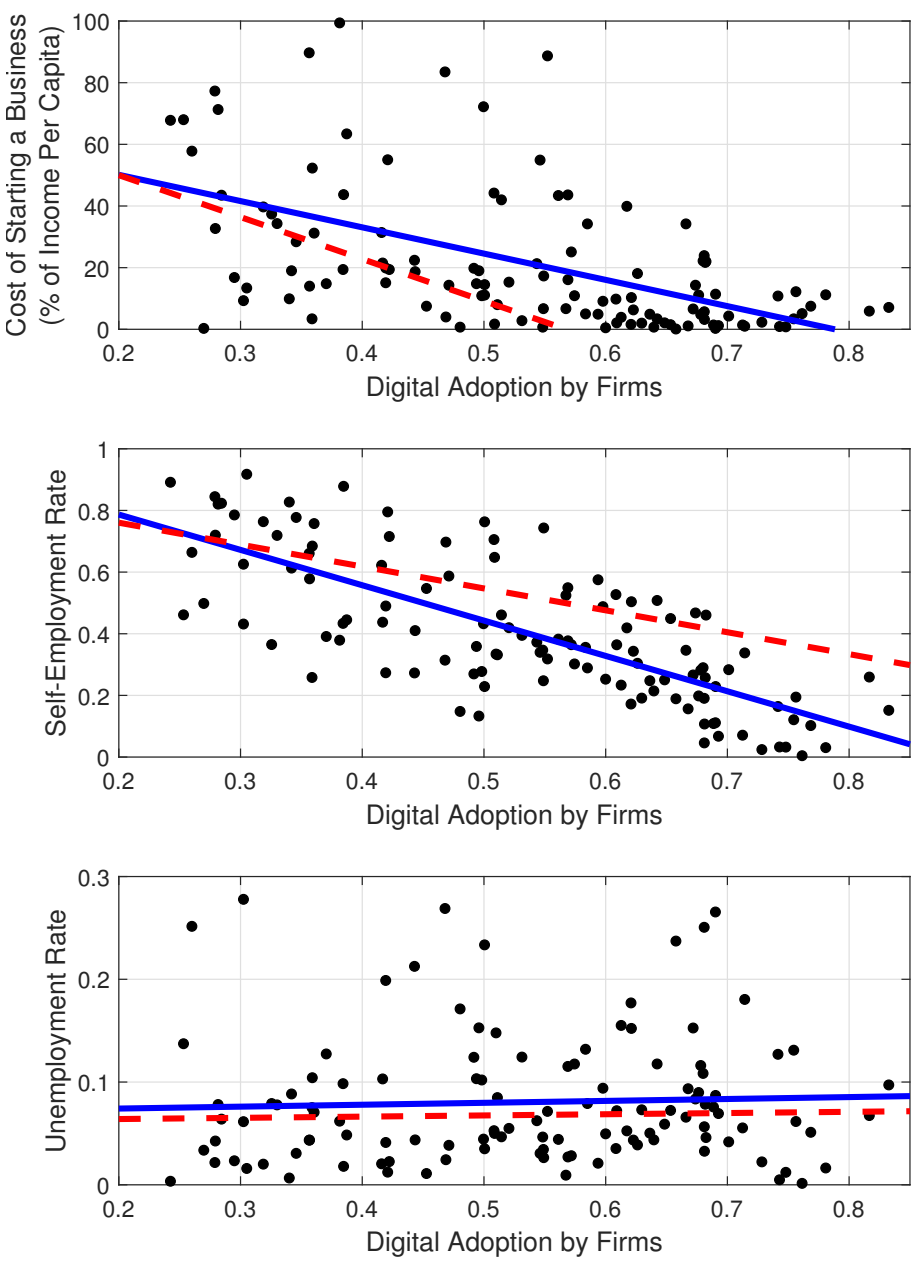

- Data Data: Linear Trend - - Model: Linear Trend 
Figure A5: ICT-Capital Technology Adoption and Labor Market Outcomes: Data vs. Baseline Model with Higher Elasticity of Substitution between Salaried and Self-Employment Output
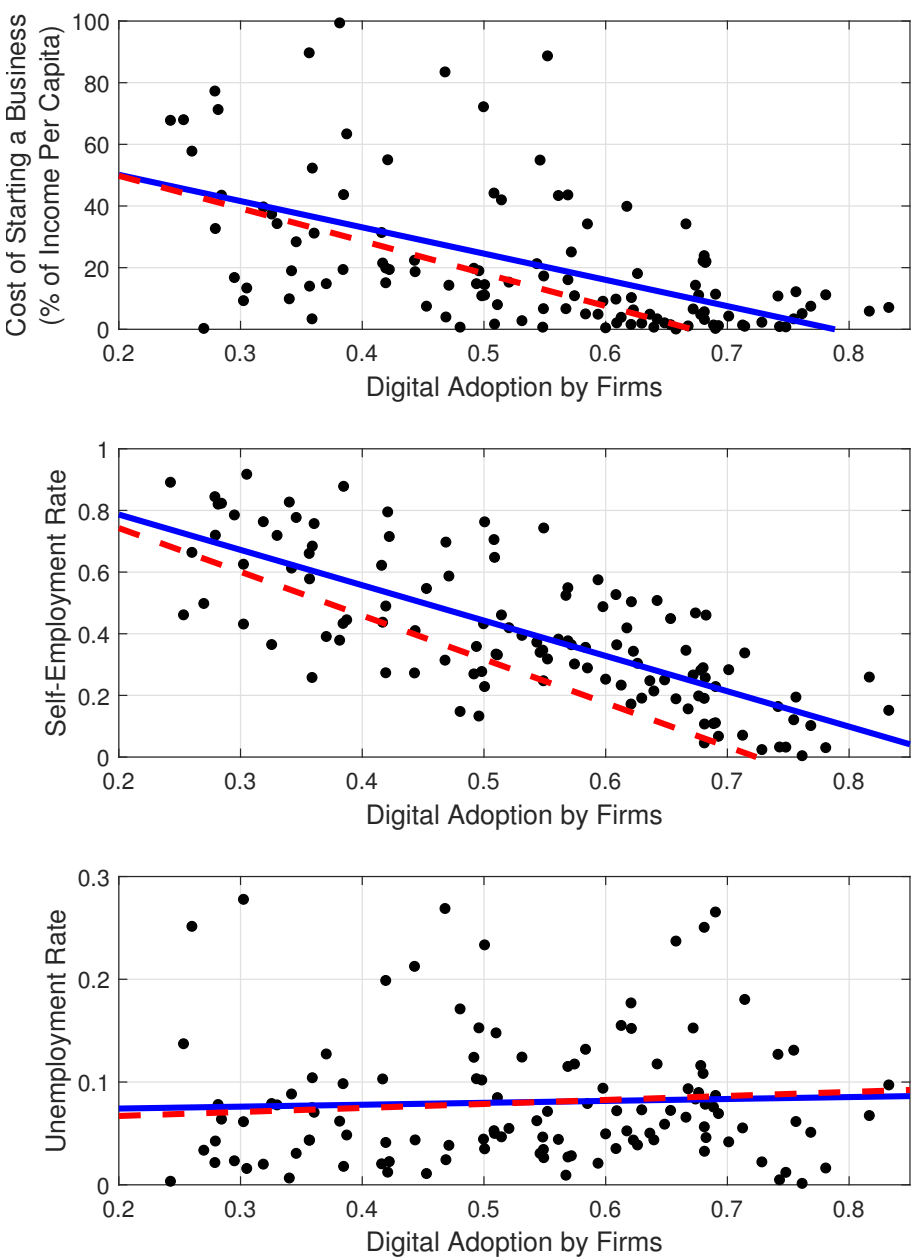

- Data Data: Linear Trend - Model: Linear Trend 
Figure A6: ICT-Capital Technology Adoption and Labor Market Outcomes: Data vs. Model, No Change in $f_{e}$
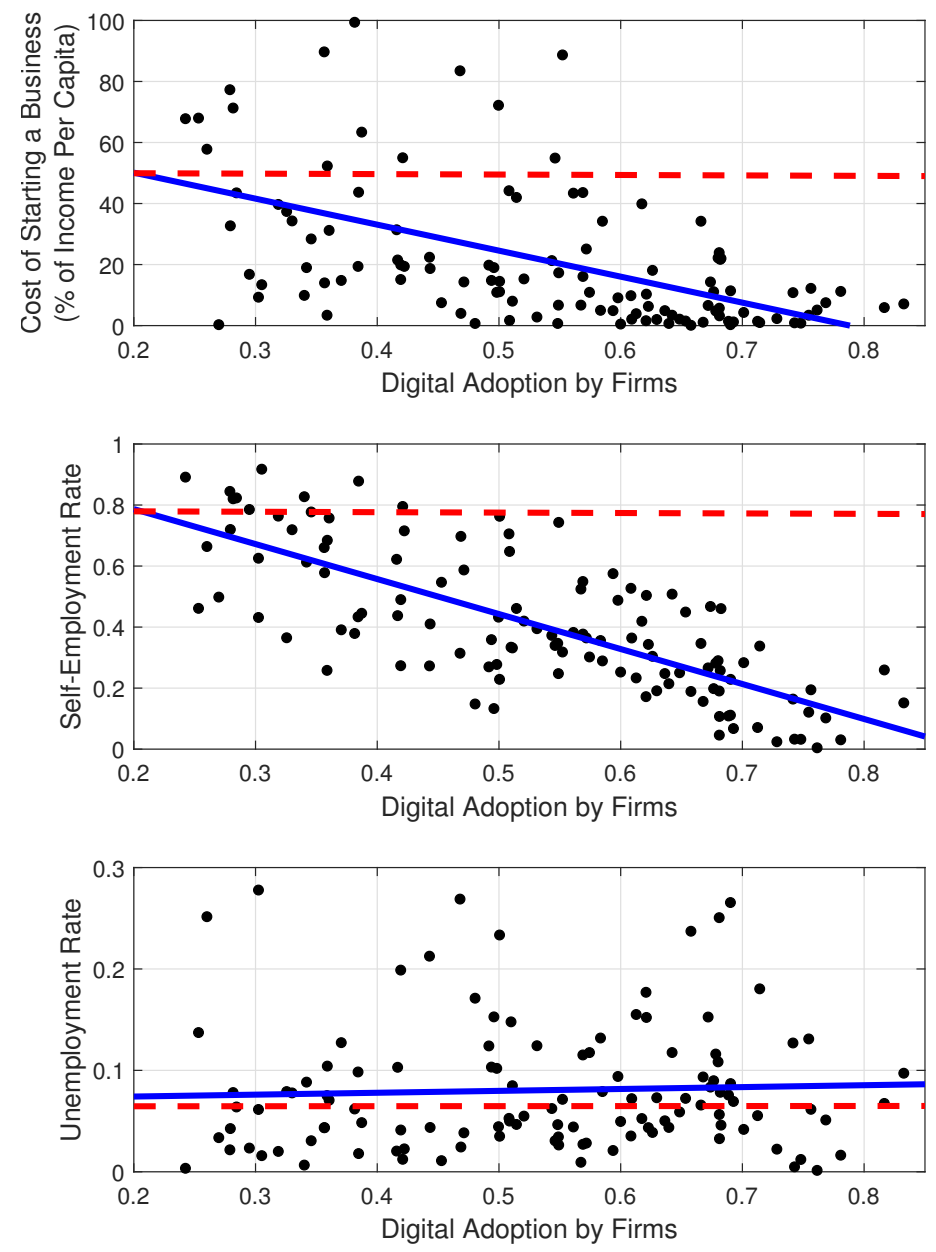

- Data $\longrightarrow$ Data: Linear Trend - - Model: Linear Trend 
Figure A7: ICT-Capital Technology Adoption and Steady-State Equilibria: No Change in $f_{e}$
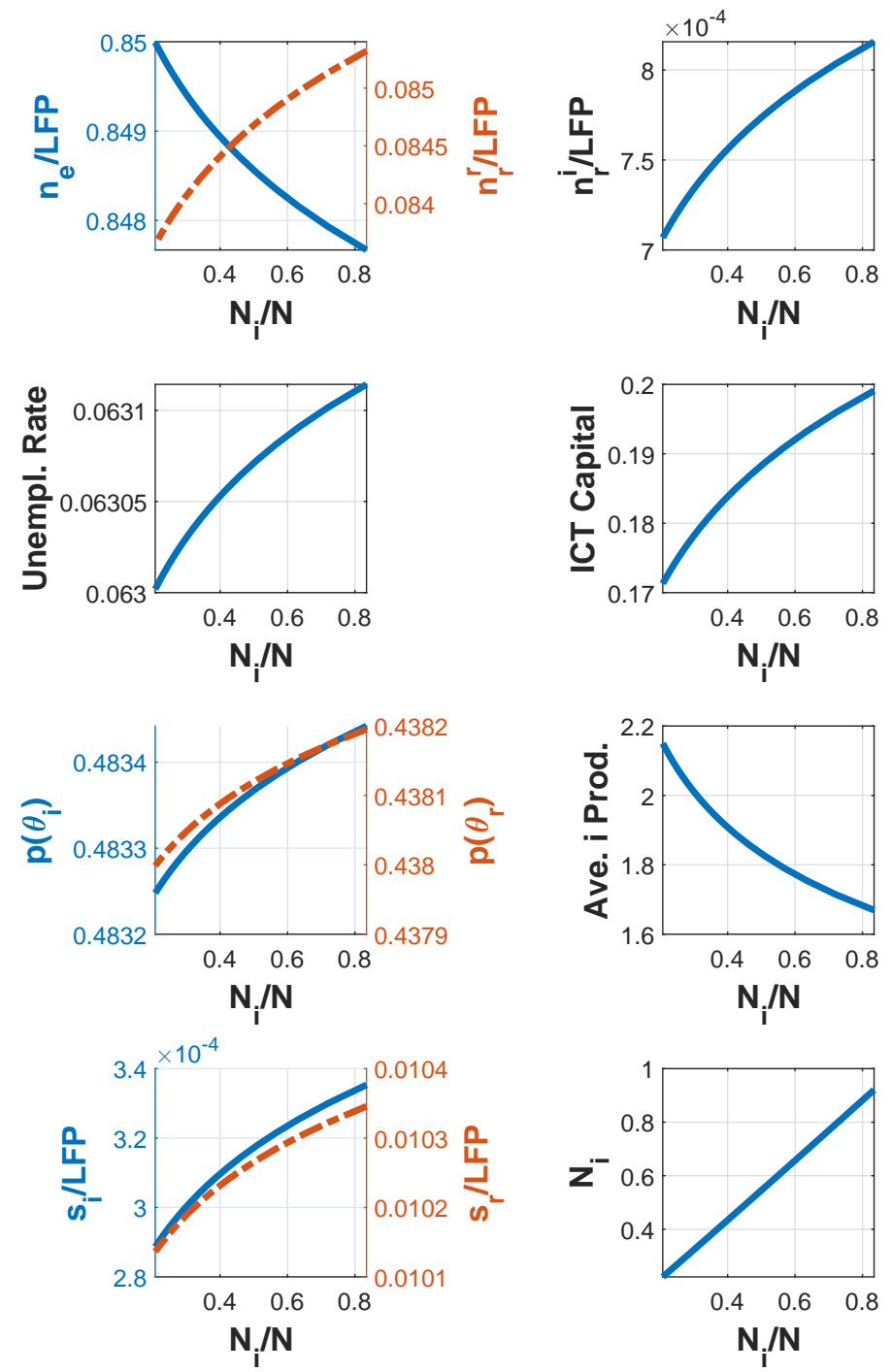
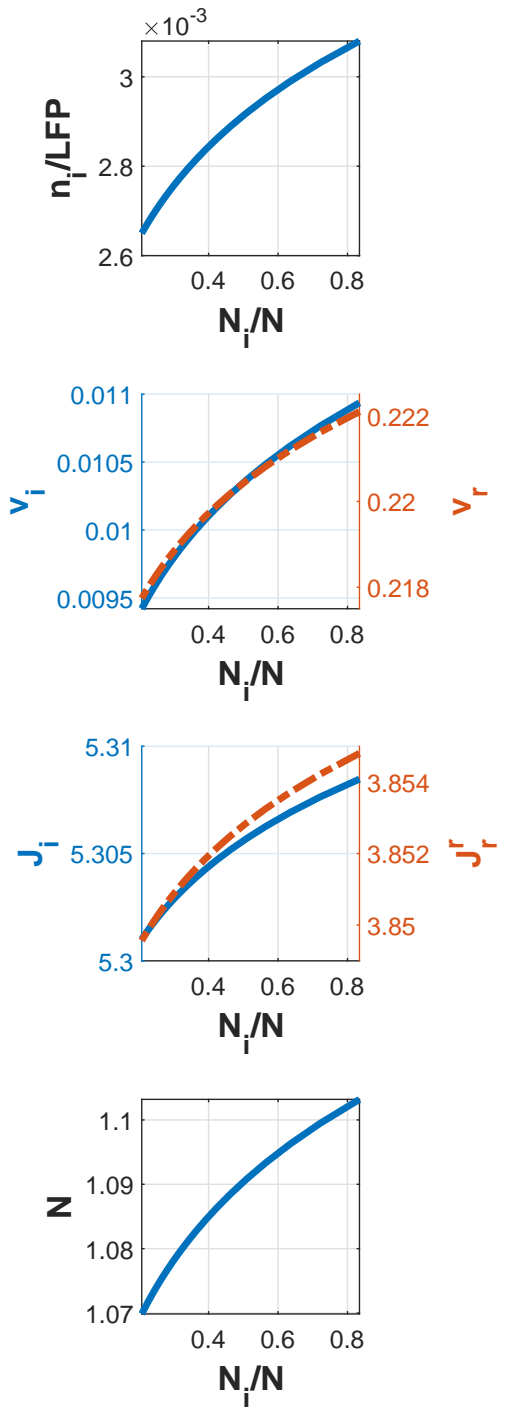
Figure A8: ICT-Capital Technology Adoption and Labor Market Outcomes: Data vs. Model with Exogenous Labor Force Participation
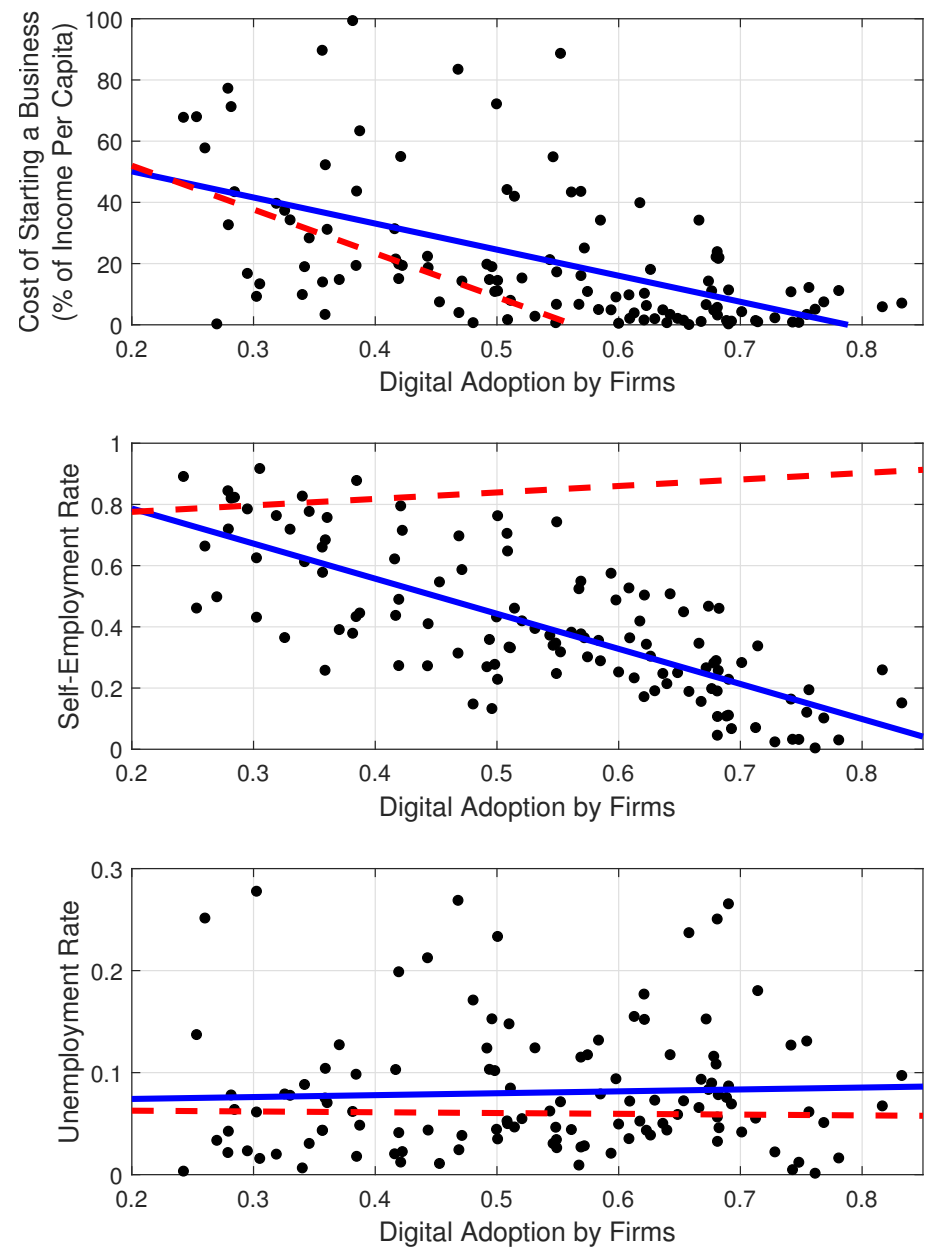

- Data - Data: Linear Trend $-\quad-$ Model: Linear Trend 
Figure A9: Steady-State Changes in Self-Employment, $N, N_{i}$, and Output: Benchmark Model and Model with Independent Sunk Entry Costs and Fixed Costs of Technology Adoption (Additional Details)
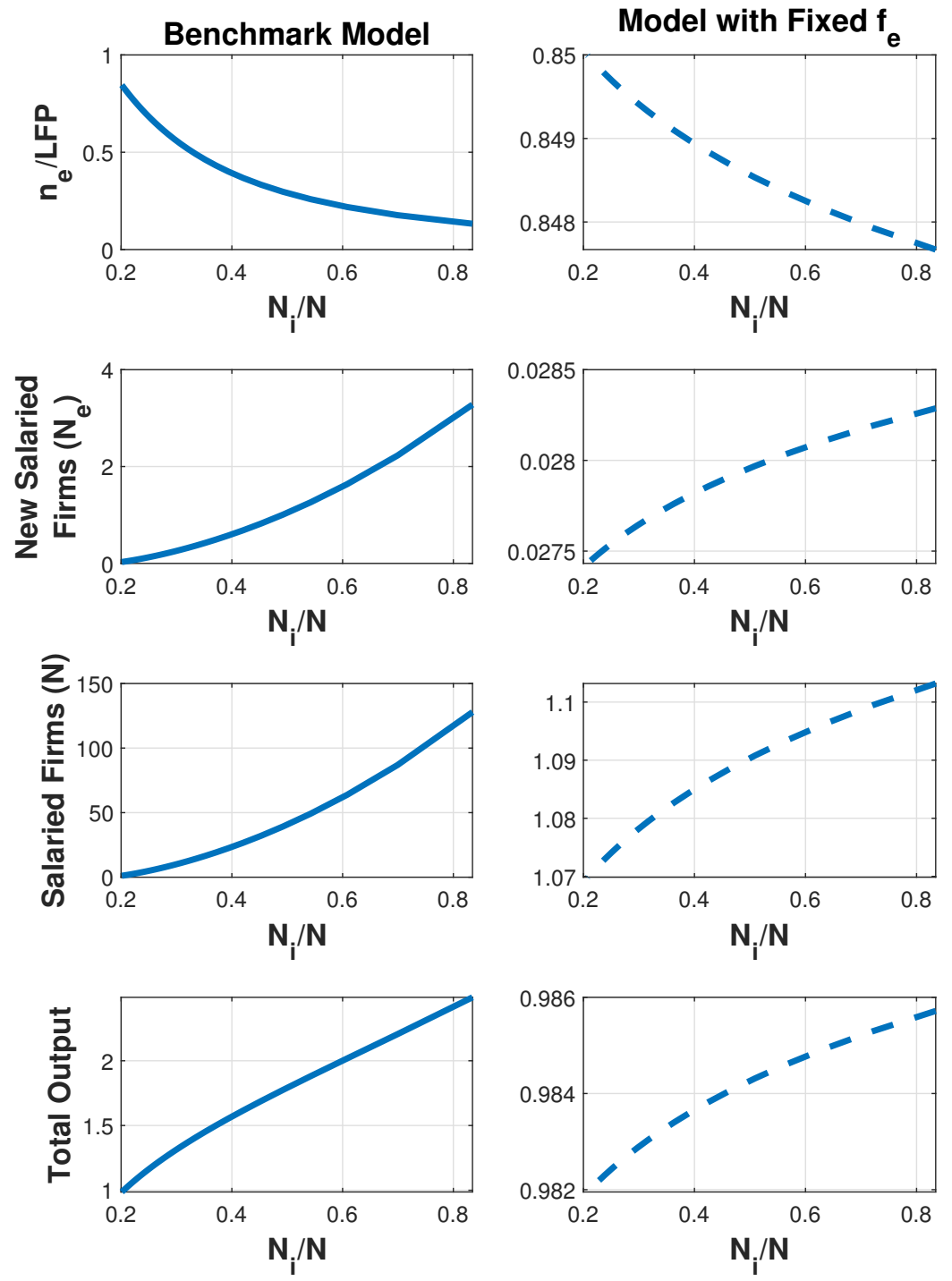
Figure A10: Self-Employment and Business Digital Adoption: Exponential Fit

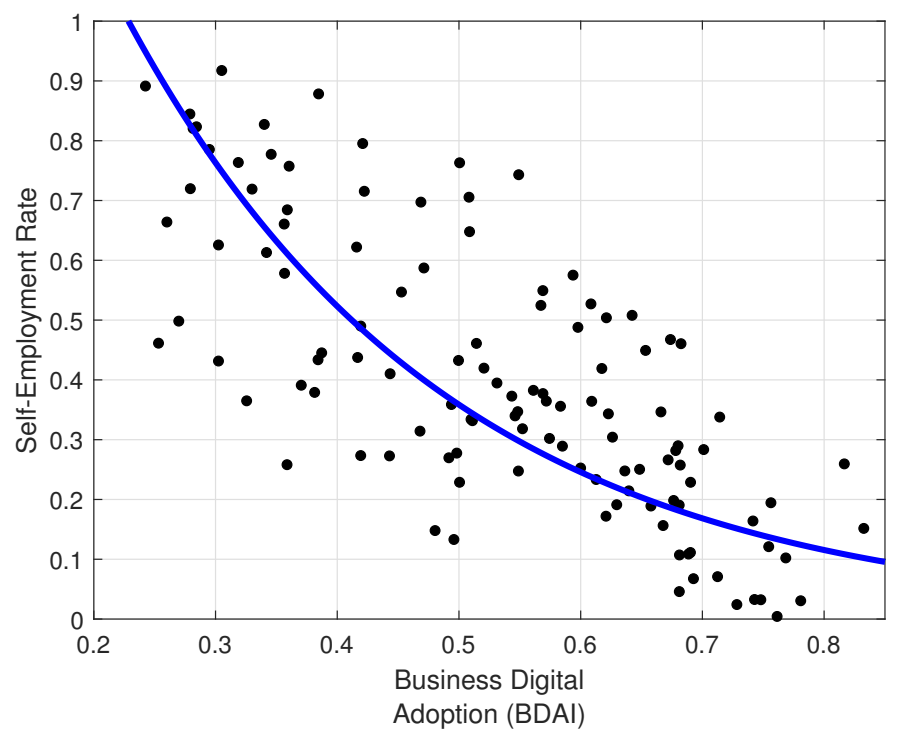

Sources: World Bank World Development Report 2016 and World Bank World Development Indicators. See Appendix A.1.1 for the list of economies used in his figure. 